\title{
Pastoralismo andino y transformaciones sociales en el norte de Chile
}

\author{
Hans Gundermann K. ${ }^{1}$
}

\section{RESUMEN}

En este trabajo desarrollamos una discusión del pastoralismo que practican las poblaciones aymaras y atacameñas del norte de Chile. Abordamos el tema desde una perspectiva dinámica; esto es, considerando la continuidad y el cambio en esas actividades. Desde esa perspectiva histórica sostenemos la hipótesis de una transformación. Esta consistiría en el tránsito de un pastoralismo entendido como un conjunto de prácticas insertas en sistemas campesinos microrregionales a un pastoralismo transformado e inscrito en un sistema social andino regionalizado.

\begin{abstract}
This work contains a discussion of the Andean pastoralism. In the north of Chile those practices are developed by aymara and atacameño indigenous populations. Is sustained that an appropriated approach to this topic is a dynamic perspective; this is, considering the continuity and the change in those activities. From that historical vision we sustain the hypothesis of a transformation. This consist in the transit of a traditional pastoralism, understood as a group of practices insert in microregionalized rural systems, to a transformed pastoralism inscribed in a regionalized Andean social system.
\end{abstract}

Instituto de Investigaciones Arqueológicas y Museo (IIAM), Universidad Católica del Norte, calle Antofagasta s/n, San Pedro de Atacama, Chile.

\section{Introducción}

El pastoralismo andino es en el norte de Chile una actividad exclusiva de las poblaciones indígenas aymara y atacameña. Puesto que estas categorías sociales se forman históricamente bajo procesos coloniales y nacionales, entre los cuales destaca la estructuración de los territorios étnicos en cuyo interior se desarrollan prácticas ganaderas, la exclusividad de su práctica por minorías indígenas y el propio pastoralismo no pueden entenderse sino como un resultado, entre muchos otros, de tales fuerzas estructurantes. Definiciones sustantivas del pastoralismo andino, entonces, sólo pueden formularse en referencia a contextos sociohistóricos que las modelan.

Lejos de constituir una realidad estática, se trata en la actualidad de prácticas dinámicas, cambiantes y heterogéneas. El cambio rápido y un incremento de diferenciación y complejidad tienen lugar en directa asociación, según postulamos, con fenómenos correlativos de transformación social de las poblaciones que desarrollan actividades pastorales. De esta manera, nos proponemos desarrollar una discusión del pastoralismo andino regional, por una parte, en perspectiva dinámica, es decir, abordando la continuidad y el cambio, la reproducción y las transformaciones de tales prácticas, y, por otra, distinguiendo niveles analíticos relacionados. Estos son, la dinámica interna de las sociedades indígenas en cuyo seno se desarrolla pastoralismo, y la dinámica externa a la cual se sujeta, en una medida significativa, la transformación social de las poblaciones aymaras y atacameñas. De uno a otro nivel reconocemos, por tanto, la actuación de fuerzas que intervienen sobre la dirección y la dinámica del cambio en las sociedades indígenas. En uno y otro plano de realidad, a su vez, detectamos factores que favorecen, 
sea la reproducción del pastoralismo, sea su transformación.

Son indispensables puntos de referencia espaciales y temporales con los cuales trazar los límites y alcances del análisis. Nos interesamos aquí por el pastoralismo andino contemporáneo que tiene lugar en el extremo meridional de los territorios occidentales de la región andina. Son territorios de alta montaña (2.500-4.500 de altitud, aproximadamente), circunscritos por desiertos absolutos ubicados al sur y al poniente donde ya no es posible el pastoralismo, por altiplanicies de altura hacia el oriente cuyas condiciones geográficas y ecológicas difieren en suficiente medida como para introducir matices diferenciadores a la actividad pastoralista que en uno y otro espacio se practica, y por una ecología de alta montaña menos árida hacia el norte, correspondiente con el límite internacional entre Chile y Perú, la cual también favorece la existencia de modificaciones notorias en los regímenes pastoriles.

Asimismo, nos interesamos por el pastoralismo actual en la región, pero entendido como el resultado de un proceso histórico. Requerimos, por lo tanto, determinar estados anteriores por referencia a los cuales establecer la continuidad y el cambio. Ellos están representados por las formas de integración política de los territorios andinos desarrollados durante el S. XIX y la primera mitad del S. XX mediante la acción de los Estados nacionales peruano y boliviano, primero, y chileno a partir de 1878, a lo que le sigue la subsecuente anexión de estos territorios conquistados a la soberanía nacional. También, por la integración económica que el desarrollo de economías capitalistas de enclave ubicadas en el desierto provocaron en las regiones andinas aledañas. Si esos son los parámetros históricos, podemos preguntarnos por el proceso que tiene lugar con el pastoralismo. Aquel puede definirse como el de una transformación: esta consistiría en el tránsito de un pastoralismo entendido como un conjunto de prácticas insertas en sistemas campesinos microrregionales a un pastoralismo transformado e inscrito en un sistema social andino regionalizado. Los antecedentes que se presentan y la discusión que siguen se dirigen a sustentar esta hipótesis.

\section{Microrregiones campesinas y pastoralismo}

El pastoralismo aquí analizado es el que se desarrolla al interior del espacio andino regional. La constitución de este último arranca de las medidas implementadas por el Virrey Toledo hacia finales del S. XVI, momento a partir del cual la estructura agraria colonial adquirió su forma característica. Sus ordenanzas condujeron a una reorganización del asentamiento y la ocupación de la tierra. A partir de ellas las poblaciones indígenas son reducidas a pueblos y tiene lugar la redistribución de sus antiguas tierras: unas, junto con bosques, aguas y dehesas se asignan a las nuevas reducciones para sus necesidades de reproducción social; otras, quedan retenidas en manos españolas. La presión de estos últimos les permitió conservar las tierras con mayor potencial para sus empresas agromercantiles. Las comunidades indígenas tenderán a prevalecer en terrenos marginales y de altura. El sistema agrario regional se compone así de dos sectores: uno español en los valles bajos dirigido a la producción para el mercado; otro indígena en la cordillera, con sus espacios vitales redefinidos y con producciones orientadas a la reproducción de la población. La renta en dinero demandada por la Corona de España, también impuesta por ese mismo tiempo, aseguró, a través del trabajo campesino formalmente asalariado, la articulación entre los dos componentes del sistema. Paralelamente, se están organizando los corregimientos, en nuestro caso los de Arica y Atacama, unidades político administrativas que también participarán en la separación de espacios regionales indígenas y en la organización del sistema de relaciones que se dan al interior y entre los sectores sociales en que se estructura la sociedad colonial.

Previo a la ordenación territorial impuesta por el régimen colonial, el sistema regional de jurisdicciones territoriales compartidas, como denominara Hidalgo (1986) al control de recursos zonales realizado por varias unidades políticas altiplánicas de filiación lingüística aymara, se desarrolló sobre sectores y puntos geográficos muy distantes entre sí: pescado y fertilizantes orgánicos en la costa marítima del Pacífico, recursos minerales del desierto y cordillera, tierras de labranza en valles y oasis, pastizales de alta cordillera para ganado, etc. Esta amplitud y variedad de recursos directa- 
mente disponibles se restringe dramáticamente, dando origen a un patrón de acceso a recursos y productos limitado a los territorios comunales. Por situarse en la gradiente altitudinal de los Andes, no fue raro que esos espacios incluyeran dos ecologías y sus respectivos recursos. Las reducciones mantuvieron disponible entonces, según un modelo con alcances puramente locales, algo de la variedad de recursos de antaño. La así llamada microverticalidad (Oberem, 1981; Salomon, 1985; Pease, 1985), dada su propia naturaleza restrictiva, presupuso articulaciones complementarias que permitieran la obtención de un conjunto más diversificado de recursos. Aquellas tenían lugar con otras comunidades, con el espacio hacendal y con áreas de recursos extractivos sujetos a dominio estatal. A medida que las reducciones se fragmentan internamente, terminando por dar origen a las comunidades republicanas del S. XIX y principios del S. XX, aumenta la especialización productiva y, por lo tanto, las articulaciones complementarias se hacen más profusas. Un patrón característico de tales prácticas es el intercambio de productos y subproductos entre localidades ganaderas de altura y agrícolas de valles y quebradas ubicadas en alturas medias.

Podemos denominar microrregiones campesinas a los espacios sociales andinos cubiertos por comunidades que producen e intercambian entre sí productos complementarios, entre ellos los derivados de la actividad pastoralista. No se trata, por cierto, de espacios cerrados, ya que mantienen grados variables de relación con otros sujetos sociales y economías (campesinas, hacendales, industriales). Se distribuyen a través de la gradiente andina en un sentido este-oeste llegando a veces a unir, mediante diversos eslabonamientos, la costa marítima y las comunidades ganaderas de la altiplanicie boliviana, o la alta cordillera y valles orientales argentinos si consideramos la situación atacameña; en ambos casos más allá de las actuales fronteras nacionales. Las relaciones toman la forma de una red más nutrida en los núcleos de las microrregiones (comunidades aymaras y atacameñas más importantes) y con nudos y nexos más dispersos y débiles a medida que se avanza hacia sus periferias. Lejos de componerse sólo por vínculos económicos de intercambio, les son también propios contenidos sociológicos (parentesco ritual, clientelas políticas) y simbólicos (congre- gaciones rituales asociadas a sistemas de fiestas religiosas, paisajes culturales comunes).

En las microrregiones indígenas alguna crianza de animales es común a todas las localidades campesinas, pero sistemas propiamente pastoriles sólo están presentes en dos contextos específicos. Por una parte, comunidades agrícolas aymaras y atacameñas de altura que mantienen sistemas coordinados de producción agrícola y ganadera y comunidades aymarás exclusivamente pastoriles existentes en el extremo norte de la región aquí analizada. Permiten esto último la existencia de recursos forrajeros concentrados y cuya disposición es más o menos estable en el tiempo, a condición de que esa especialización productiva se combine con sistemas de intercambio microrregionales operativos. La dispersión de recursos forrajeros con una disposición más incierta de ellos $\mathrm{y}$, por lo tanto, constituyéndose en una actividad más riesgosa, presiona hacia la obtención de una base productiva más diversificada. Por su parte, el control de una base más amplia de recursos productivos aumenta la autosuficiencia y disminuye la dependencia de las microrregiones, cuyas redes tenderán a estructurarse de manera más laxa.

Si analizamos en un sentido latitudinal los factores y relaciones aludidos, se advertirá que las condiciones geográficas y ecológicas se hacen más extremas de norte a sur. En el área meridional de Tarapacá y en la cordillera andina de Atacama la oferta forrajera es relativamente más pobre, considerablemente más dispersa y su volumen es altamente inestable de año en año; todo lo anterior, en combinación con condiciones climáticas estacionales críticas. Siendo esto así, las unidades de producción ganadera requieren, por una parte, integrar de manera muy estrecha producción agrícola y pecuaria mediante la provisión de alfalfa y de desechos agrícolas aprovechables por el ganado. Esta posibilidad también está abierta para el caso de las comunidades agroganaderas localizadas en las cabeceras de las quebradas del norte de Tarapacá y de Arica. La vertiente occidental de los Andes donde estas comunidades se localizan presenta condiciones de mayor aridez que la alta cordillera y la provisión forrajera anual depende de precipitaciones que se presentan de manera muy irregular. Por otra, cuando ello es posible, las unidades productivas deben complejizar las estrate- 
gias de trashumancia sobre áreas o islotes forrajeros distribuidos de una manera crecientemente dispersa y flexibilizar la propia trashumancia ajustándose a ciclos anuales de mayor o menor humedad.

Podemos ejemplificar las relaciones planteadas presentando los casos de la comunidad histórica de Isluga y los altos de Arica, analizados hace ya años por el autor (Gundermann, 1984) y el de una comunidad atacameña como la de Socaire, estudiada por Folla (1989).

\subsection{El sistema pastoralista tradicional en la zona andina aymara}

En las proposiciones precedentes se introdujeron tres unidades de análisis: primero, la microrregión campesina en cuanto un tipo de espacio social característico de la estructura del espacio andino regional en un momento anterior al proceso de regionalización de la sociedad indígena; luego, las comunidades históricas como organizaciones socioterritoriales cuyas relaciones económicas, sociológicas y simbólicas recíprocas conforman las microrregiones y, por último, las unidades de producción ganadera, de base familiar, que desarrollan actividades pastoriles en marcos de acción definidos por las comunidades de pertenencia. Para poder describir adecuadamente el sistema pastoralista aymara y atacameño es necesario incorporar, además, unidades suplementarias. La estancia en los casos de zonas ganaderas exclusivas y la dualidad chacra-estancia en sistemas pastorales mixtos son tipos de unidad espacial en torno a las cuales se organiza la actividad ganadera y que median la relación entre unidad de producción y comunidad.

Las reducciones y resguardos indígenas coloniales de la alta cordillera andina de Arica y Tarapacá estructuraron el pastoralismo a través de un sistema de estancias. Las estancias en esta zona son, desde un punto de vista ecológico, espacios con producción vegetal potencialmente utilizables en la crianza regular de camélidos sudamericanos (llamas y alpacas) y ovinos; desde uno jurídico, propiedades rústicas constituidas, normalmente de gran extensión (unas 220 en total, de las cuales la mayoría oscila entre unas 1.000 y 8.000 has.), las cuales se mantienen como sucesiones indivisas; desde uno económico, el lugar principal de la producción campesina y la reproducción social de las unidades domésticas; desde uno sociológico, un conjunto de unidades domésticas de tamaño variable unidas por filiación patrilineal, conformando entre uno y cuatro, normalmente, pequeños patrilinajes localizados; $y$, desde uno cultural, un núcleo de condensación de mundos de experiencia de vida.

De manera característica, cada estancia contiene en su territorio una combinación de asociaciones vegetales relacionadas, en una geografía de montaña, con pisos altitudinales. La terminología local en Isluga, ${ }^{2}$ por ejemplo, discrimina entre waña, zuni y palle, que se corresponden, en términos gruesos, con pisos vegetacionales. Al piso puneño (2.800-3.800 m. snm) corresponde waña; al piso altoandino (3.800-4.800 m. snm) se conecta zuni y al subnival (4.800 m. snm y más) se asocia paye. Hay una concordancia estrecha, por lo tanto, entre las categorías vernáculas y las sistemáticas elaboradas por la biología. Una asociación vegetal importante desde el punto de vista pastoril es la vega o humedal altoandino (hok'o en lengua aymara) que, por depender de cursos de agua corrientes, no tiene una asociación específica con pisos altitudinales y sus vegetaciones características. Estos pisos vegetacionales y asociaciones vegetales mantienen ofertas forrajeras diferenciadas con variaciones anuales que también les son propias.

Las estrategias pastoriles se realizan en concordancia con las ofertas y las variaciones forrajeras en el territorio de cada estancia. Estas varían en un sentido latitudinal ${ }^{3}$ y longitudinal. ${ }^{4}$ Las combinaciones más típicas son las de aquellas estancias que integran porciones de piso puneño y altoandino, más algunas vegas y las que se sitúan por entero en el piso altoandino incluidos los humedales. El piso altoandino en sectores medios

2 Comunidad histórica aymara localizada en el piso altoandino junto a la frontera con Bolivia en el sector nordeste de la Provincia de Iquique.

3 Mayor aridez a medida que pasamos desde la puna seca en el extremo norte de la zona, a una puna más árida y salada en el sector medio y meridional del territorio andino aymara.

$4 \quad$ El pie de monte de la cordillera andina es un desierto marginal de altura que se hace menos árido a medida que se asciende hacia los pisos puneño y altoandino. 
y meridionales, comparativamente más árido, permite principalmente la crianza de llamas sobre praderas muy amplias; a esa variedad de camélido doméstico se le reconoce gran rusticidad y capacidad de cubrir las normalmente extensas superficies que las estancias tienen en esa zona. A medida que nos desplazamos hacia el área norte aumenta la proporción de alpacas, más especializadas y dependientes de vegas y de vegetación originada en cursos de agua corriente. Los ovinos, por su parte, como especie exógena más sensible a los rigores estacionales en el piso altoandino, son incluidos en los rebaños de las unidades domésticas sobre todo de aquellas estancias que cuentan con piso vegetacional puneño. Sólo sus comparativamente mucho más rápidos ciclos de reproducción justifican el interés en mantenerlos ya que, además, demandan pastoreo más intensivo.

Una considerable variación estacional se presenta en las cubiertas vegetales de la pradera andina y de las vegas. Estas detienen su ciclo vegetativo al inicio de la estación fría, ya a finales de abril e inicios de mayo; un mejoramiento en las temperaturas promedio, ostensible ya en septiembre, reactiva la producción vegetal, alcanzando su cúspide en los meses de mayor humedad (enero y febrero). Las praderas de secano, enteramente dependientes de las lluvias tanto en el piso puneño como en el altoandino, generan desde finales de enero una cubierta herbácea de gramíneas y algunas leguminosas, la cual madura en marzo y abril. Los meses más fríos (junio a agosto) y el inicio de una temporada más cálida (meses de septiembre a noviembre) conforman una estación fría y, en cualquier caso, seca y con pocos alimentos para el ganado. La estrategia seguida en este caso es la dispersión de los rebaños de llamas, alpacas y ovejas a diferentes sectores cubriendo espacios y asociaciones vegetales distintas. Cuando ha habido lluvias abundantes, se practica en el sector medio del área aymara que analizamos la trashumancia a las cabeceras de los valles occidentales; se trata de praderas que en esas ocasiones se encuentran sujetas a una presión ganadera baja y presentan una oferta forrajera abundante. Consisten de zonas abrigadas, por lo que permiten sortear mejor los meses fríos. Durante la estación de mayor abundancia (diciembre a mayo) la estrategia general del pastoralismo es por completo opuesta: se trata ahora de concentrar los rebaños en praderas y vegas con cubiertas vegetales más abundantes y palatables.

Una composición más adecuada de recursos forrajeros es provista por una variedad de asociaciones vegetales cuyas ofertas alimentarias resulten complementables a lo largo de los ciclos vegetativos. Oferta variada y complementable favorece el logro de una seguridad productiva relativamente más alta $\mathrm{y}$, dado lo anterior, permite beneficiarse de una gama muy amplia de productos y subproductos pecuarios provistos por las tres especies principales (llamas, alpacas y ovinos). Hasta donde tal ecuación es realizable en esas condiciones geográficas (máxima seguridad posible mediante una máxima variedad de producción pecuaria), representa una fórmula satisfactoria para un tipo de campesinado con economías poco mercantilizadas que depende todavía en amplia medida de la autoproducción para satisfacer muchos de sus requerimientos de consumo, reposición y gasto. Las estancias, por lo tanto, tenderán a conformarse históricamente como territorios que posibilitan producciones pecuarias diversificadas. De no ser este el caso, materias primas y productos no autoproducidos deberán obtenerse por vía de trabajo, intercambio y, en menor medida, por compra con dinero. La búsqueda de un equilibrio positivo entre seguridad y diversidad productiva parece ser la razón principal por la cual las estancias se han dividido tan poco durante los últimos tres siglos, manteniendo muchas de ellas aproximadamente la misma composición territorial original de principios del S. XVIII (Gundermann y González, 1997).

En los escenarios sociales de antaño los rebaños generaron productos, subproductos y servicios centrales para la vida social aymara: medios de transporte, alimentos y materias primas diversas. Buena parte de ellos eran utilizados y consumidos internamente. En cuanto al transporte, la relación económica con otras comunidades se realizaba utilizando esa capacidad de carga (recuas de llamas machos cargueros, pero también burros y a veces mulas), intercambiando y/o vendiendo bienes como carne, tejidos, cordelería, en algunos sectores productos agrícolas de altura y, en ocasiones, bienes producidos en otros sectores y trasladados por los pastores con fines de intercambio o comercio. El traslado a las zonas agrícolas per- 
mitía obtener granos (trigo, maíz) y frutas, además de efectuar trabajos para los clientes de los valles pagados usualmente en productos. Momentos festivos eran ocasiones para un incremento de estas relaciones, ampliando también las posibilidades de participación (por ejemplo, como visitantes, promesantes, músicos, etc.).

\subsection{El sistema pastoralista en la zona atacameña}

La relación chacra-estancia queda bien representada por el caso atacameño, aun cuando no es exclusiva de ese sector pues la comparte con las comunidades mixtas de las cabeceras de los valles de Tarapacá y Arica. En efecto, aquí como allá, las características de las praderas naturales es tal que una masa ganadera comunal de cierta importancia no puede, salvo en años excepcionalmente húmedos, depender sólo del alimento provisto por esas praderas. Un arreglo que incrementa sustancialmente la estabilidad de masa del rebaño es el de complementar su alimentación con restos de cosecha y con alfalfa. Con ello, asimismo, puede mantenerse un volumen de masa más alto que si no se contara con este complemento. Comunidades con recursos forrajeros naturales limitados ${ }^{5}$ tienen en los forrajes originados por la agricultura la base estable de la crianza, en tanto que las praderas naturales representan un complemento excepcional. Según el incremento de la aridez ambiente se manifiesta, por tanto, una gradiente de mayor a menor dependencia de fuentes artificiales de alimentación del ganado. Comunidades de altura que incluyen o bordean el piso altoandino pueden contar con la posibilidad de criar animales para los cuales los recursos forrajeros naturales representan una fuente estable de alimentos, aunque variable, de año en año y según ciclos de sequía-humedad. Esa propiedad se hace cada vez más insegura y, por lo tanto, desechable como alternativa de estrategia pastoril estable, a medida que se desciende en altura hacia occidente.

No obstante que el patrón general de integración entre chacra ${ }^{6} y$ estancia ${ }^{7}$ que se acaba de esbozar es común a todo el flanco occidental de la cordillera de los Andes, éste se especifica con variantes y detalles que resulta de interés conocer. El factor de variación más obvio y del cual ya se hizo mención es el cambio en la cantidad y en la regulari- dad de las lluvias estivales responsables del crecimiento de las praderas y de la recarga de vertientes y aguadas, según nos desplazamos de este a oeste, bajando en altura, o de norte a sur, ganando en latitud. ${ }^{8}$ De esta manera, las comunidades puramente agrícolas del pie del desierto nos llevan, en realidad, a salirnos del pastoralismo andino para reconocer una actividad de crianza de algunos animales semiestabulados, prácticas que poco o nada deben a los sistemas pastoriles históricos andinos que aquí analizamos. Otro elemento, de carácter estructural, está representado por el proceso de constitución de propiedades ganaderas de carácter sucesorial en las cabeceras de los valles, un fenómeno ligado a la regularización de la propiedad impuesto por el Estado chileno a finales del S. XIX. Es una situación exclusiva del extremo septentrional de la zona aymara. Las unidades sociológicas que ejercen el dominio sobre esos segmentos territoriales se corresponden con parentelas miembros de comunidades históricas. Buenos ejemplos los encontramos en los altos de los valles de Camiña, Chiapa, Codpa y Putre.

Otros aspectos que conllevan variación los detectamos internamente. Unos se relacionan con regímenes de crianza variables que aprovechan las condiciones de rusticidad y manejo de las especies. Las llamas, único camélido doméstico que prospera en condiciones de aridez como éstas, suelen depender mucho más de pastos naturales y su pastoreo es usualmente laxo y poco exigente;

Por lo común en cotas de altura más bajas correspondientes con el piso prepuneño. Son lugares que se hacen cada vez más áridos a medida que se baja hacia el desierto absoluto y que nos desplazamos en un sentido norte-sur.

6 Proveedora de alfalfa y de residuos de cosecha.

7 Que en estos casos nombra con propiedad a sitios de pastoreo dotados de algún potencial forrajero y aguadas al interior de un territorio árido más amplio y no a territorios multiecológicos ocupados por los rebaños de linajes con arreglo a estrategias complejas de integración de la variación ecológica del territorio, como analizáramos para Isluga.

8 Los ciclos se desarrollan, según lo estableciera Gaete (1974) con registros que forman una serie de medio siglo, según una periodicidad variable de 5-8 años, en los cuales a un par de años de mayor humedad siguen otros con pocas o nulas precipitaciones; todo ello bajo el telón de fondo de un ciclo más amplio de desecación general del territorio según lo sugieren los datos analizados. 
en tal caso tienden a ser dejadas en sectores de cerros altos cercanos a pasturas y aguadas y su vigilancia corre a cargo de los varones de los hogares propietarios. Ovinos y, a veces, caprinos, en cambio, cuando se los mantienen en praderas naturales exigen un pastoreo más prolijo (conducción, vigilancia, "repunte", encierro nocturno, etc.), el mismo que se simplifica parcialmente cuando consumen forrajes producidos, en corrales o en las propias parcelas de alfalfa. Otros dependen de la variación estacional de la capacidad de carga de las praderas y de la producción de forrajes artificiales. Las hierbas que pueblan las praderas que se forman con posterioridad a las lluvias de enero y febrero liberan hasta el mes de mayo, aproximadamente, la presión sobre la alfalfa, con lo cual aumenta la movilidad de los rebaños de estancia a estancia y también intensifica las actividades de pastoreo. Con los meses fríos la pradera se ha agotado, efectuándose entonces un retorno progresivo (cada ciertos días, un rato por día, etc.) a parcelas con restos de cosecha o alfalfa o simplemente a corrales donde se les provee de siempre bien medidas raciones de alimento; este régimen de dependencia de forrajes artificiales se prolonga hasta la nueva temporada de lluvias. Si estas faltan, cuestión regular según las características de los ciclos que ya describiéramos, la dependencia de la alfalfa aumenta, presionando con fuerza sobre sus existencias.

La trashumancia tiene lugar en tales contextos sólo cuando hay lluvias y forrajes en alguna abundancia. Si no, sólo puede optarse por una trashumancia circunscrita a islotes de forraje disponibles estacionalmente de manera regular (vegas), por lo común distantes. El caso de la comunidad atacameña de Socaire, cuyo pastoralismo fue detalladamente descrito hace años atrás por J. C. Folla, manifiesta un sistema de trashumancia flexible, abierto, en el cual varias estrategias son posibles para responder a las características que adopta cada ciclo anual, permitiendo incluso ajustes importantes dentro de una misma temporada. Formas muy elaboradas de trashumancia están presentes en esa comunidad, en coexistencia y a veces sucediendo o precediendo estrategias de manejo alimentario no trashumante o de trashumancia limitada. ${ }^{9}$ Por una parte, tenemos la trashumancia hacia la alta cordillera (pasturas localizadas entre 3.500 - 4.500 m.snm) durante la estación cálida detrás de sitios con vegas y, si es el caso, praderas de hierbas naturales estacionales. Dadas las extremas condiciones de temperatura del piso altoandino, sus recursos forrajeros no son en definitiva aprovechables sino cuando esas condiciones térmicas han mejorado (desde octubre o noviembre); se trata entonces de formas de trashumancia para aprovechar recursos que en otro momento serían inaccesibles.

Una segunda modalidad es la de la trashumancia de invierno (es decir, durante los meses fríos desde mayo a septiembre) hacia sectores inferiores de la comunidad de Socaire, hasta llegar, bajo los $3.000 \mathrm{~m}$. snm, a las inmediaciones del gran Salar de Atacama. Se trata en este caso de aprovechar pastos naturales disponibles en el evento de que se hayan producido lluvias estivales. Se trata de desplazamientos a estancias situadas una o, como máximo, dos jornadas de marcha en dirección al oeste y noroeste. Según el parecer del autor, en el pasado, trashumancias de verano y de invierno formaban sólo dos momentos de un sistema de trashumancia integrado. En la actualidad, esta integración es sólo parcial ${ }^{10}$ y su disociación parece responder al doble impacto de la habilitación de campos de alfalfa relativamente extensos ${ }^{11}$ y a una tendencia general al desecamiento que, por una parte, obliga a depender cada vez más de los campos de alfalfa y, por otra, hace inestable y no siempre en el volumen suficiente el recurso al forraje

9 Se consigna el ejemplo de un pastor que condujo un rebaño mixto de unas 200 cabezas siguiendo un periplo de trashumancia que lo fue internando hacia el sur y sureste por la alta cordillera andina a sitios distantes 10 jornadas de marcha en la frontera con Argentina. En su camino pasó por otras tantas estaciones intermedias. El traslado demandó las jornadas de marcha y algo más del doble de ese tiempo gastados en estadías de varios días allí donde había pastos en mayor abundancia; en total, 33 días. El retorno, siguiendo el mismo periplo, tuvo lugar a finales de marzo, momento en el cual el frío expulsa los rebaños de la alta cordillera (op. cit.: 138-146).

10 Sólo una fracción de los hogares de la comunidad trashuma y, de ellos, sólo una fracción practica las dos formas de trashumancia de manera secuencial.

11 En su momento desarrollados para beneficiarse de la necesidad de pastos que los arreos de ganado bovino provenientes de Argentina requerían para reponerse y continuar su tránsito hacia las factorías mineras del desierto. 
provisto por las praderas naturales. Otras modalidades de manejo ganadero presentes en Socaire no son sino variaciones del uso exclusivo de alimentos artificiales, administrados en potreros o estabulados y en asociación o no con el uso de pastos naturales. La variación en las estrategias de manejo de los rebaños presenta entonces algunos patrones generales (nivel de la comunidad), pero en planos de análisis más específicos (unidades domésticas) se advierte una gran variabilidad, dependiente de las lógicas de los hogares y sus posibilidades: estas representan formas propias de realizar el pastoralismo andino o, a veces, simplemente no practicarlo.

En comunidades agrícolas aymaras de altura la trashumancia se limita al uso de los pastos de temporada para ovejas y cabras en planicies y serranías cercanas, ubicadas a mayor altura que la caja de quebradas en cuyo fondo se encuentran cultivos y empastadas artificiales. Es equiparable, también, con la trashumancia que desde sitios como Isluga o Cariquima (3.900-4.100 m.snm) en la frontera con Bolivia (alta cordillera de la Provincia de Iquique), se practica entre abril y septiembre-octubre, sobre todo en años lluviosos, hacia las cabeceras de los valles ubicadas en el occidente en alturas similares, aunque con temperaturas menos gélidas. Guardando reserva acerca de diferencias de detalle, se trata de prácticas equivalentes a la trashumancia de invierno de Socaire. La trashumancia ascendente que resumiéramos, en cambio, se parece más a las prácticas homólogas mediterráneas. ${ }^{12}$

\subsection{El pastoralismo, las economías campesinas tradicionales y los sistemas microrregionales andinos que los articulaban.}

El nomadismo no caracteriza el pastoralismo tradicional en los Andes suroccidentales. La trashumancia de larga distancia es una práctica de manejo ganadero conocida, pero es practicada en ciertos lugares y sólo como una entre otras estrategias

Según esto, la comunidad andina de Socaire representaría el ejemplo más septentrional de un modelo de trashumancia que, practicado en las montañas de España, se adapta a la cordillera andina del centro de Chile. Confróntese al respecto Baraona, Aranda y Santana, 1961. utilizables en respuesta a condiciones ambientales áridas y a oscilaciones climáticas cíclicas. Lo define, de manera más amplia, el manejo multiecológico, con frecuencia sobre espacios relativamente restringidos correspondientes con comunidades o estancias. Complementariamente, como se acaba de ver, se acude al empleo de patrones de pastoralismo flexibles y acomodaticios a múltiples circunstancias que le dan capacidad de reacción rápida y eficaz ante contingencias de cualquier tipo. La integración, cuando ello es posible, de fuentes múltiples de alimentación del ganando es también una constante. En la propia composición de los rebaños está presente el mismo principio: varias especies y subespecies presentes en rebaños de composición mixta permiten aprovechar una base más diversificada de productos y subproductos pecuarios, pero al mismo tiempo amplían los márgenes de seguridad productiva distribuyendo los riesgos frente a los avatares climáticos. En definitiva, el aprovechamiento exhaustivo de recursos forrajeros según patrones técnicos y sociales flexibles que permitan adecuaciones oportunas ante contingencias sociales y ambientales es lo que caracterizó de manera más integral al pastoralismo andino tradicional en estas regiones extremas. El objetivo buscado es el de incrementar los márgenes de seguridad productiva y la continuidad de la explotación campesina. Un patrón pastoralista con estas características surge históricamente como una respuesta indígena a un sistema colonial (a fines del S. XVI y principios del XIX) y a sus prolongaciones republicanas. La dominación colonial y la republicana temprana reestructuran las unidades sociales y la organización de los territorios agrícolas y pastoriles y, por otra parte, imponen exacciones bajo la forma de un fondo de renta.

De manera característica, entonces, el pastoralismo tradicional radicó en economías campesinas cuyas unidades sociales fueron hogares unifamiliares, las cuales, para ciertos momentos de los ciclos pecuarios, incorporaban fuerza de trabajo complementaria reclutada, por lo común, a través de relaciones de parentesco. Ese pastoralismo podía ser una actividad productiva exclusiva (como en la zona aymara de alta montaña) o mixta (en la zona atacameña y comunidades aymaras de cabeceras de valles y de altiplanicies bajas). En ambos casos, es en la autoproducción que se gestan los fondos calórico (bienes de consumo humano, espe- 
cialmente alimentos), de reposición productiva (los recursos consumibles que se requiere preservar para culminar con éxito un nuevo ciclo productivo), social (en función del cumplimiento de obligaciones sociales) y de renta (demandado por un poder exterior con capacidad de exacción), según la terminología consagrada por Wolf (1971). Como máximo, aquéllos se alcanzaban en niveles microrregionales mediante prácticas de intercambio y trabajo (asalariado o por productos) con otras economías campesinas o a veces en unidades sociales empresariales (agropecuarias o industriales). Aunque estaba lejos de ser completa, al interior de estos espacios microrregionales los hogares y los grupos de parentesco gozaban de un grado notorio de autonomía. En lo económico, ella consistía en la producción dirigida principalmente hacia el consumo y el intercambio campesino; en una dimensión social como la del parentesco, la endogamia comunitaria y étnica era casi completa, y en lo cultural, los ritos y fiestas religiosas seguían integrando simbólicamente a los individuos a sus comunidades y a los espacios microrregionales mediante la formación de congregaciones rituales ampliadas.

Esa autonomía se transforma radicalmente durante la segunda mitad del S. XX. Ella no ocurre, sin embargo, en ausencia de cambios previos. Uno de ellos es la articulación de las comunidades aymaras y atacameñas a las economías capitalistas de los enclaves salitreros instalados en la meseta intermedia desértica ubicada entre la costa del Pacífico y los Andes. Esa vinculación estructural no fue uniforme y afectó principalmente a las comunidades de la precordillera andina. De manera un tanto más atenuada, sus efectos también se hicieron sentir en las comunidades de las cabeceras de los valles y el piso altoandino, áreas en las cuales el pastoralismo andino retenía mayor importancia. Esa articulación se dio a través del mercado: de fuerza de trabajo, constituyendo el trabajo asalariado un componente estructural de las economías campesinas de esas comunidades, además de propiciar la proletarización definitiva de un cierto número de campesino; de consumo humano, modificando paulatinamente los patrones de consumo, y de productos campesinos (hortalizas, pero también alfalfa para animales de trabajo ocupados en las actividades extractivas). A esta nueva estructura se añade la apertura social y una rela- ción más fluida con instituciones culturales y universos simbólicos modernos. Esa forma de articulación estructural, vigente desde finales del S. XIX, sin duda modifica las actividades agropecuarias realizadas en las comunidades vecinas a las factorías salitreras: lo que pudo haber de pastoralismo andino en ellas lo transforma en función de los requerimientos de las economías mineras de los enclaves. Por ejemplo, en función de esas unidades empresariales demandantes de productos campesinos se produjo la especialización agrícola dirigida a abastecer la población minera o la reconversión de la producción pecuaria desde los camélidos a los ovinos, mejor cotizados en esos mismos mercados.

Aunque en su conjunto más aisladas, las comunidades de la alta montaña no quedaron totalmente al margen de la relación con las empresas mineras ubicadas más allá de sus microrregiones campesinas. Se desarrolla en competencia parcial con la de los camélidos la producción ovina para abastecer de carne fresca la población trabajadora de la zona salitrera. Se modifica de esta manera el patrón de producción pecuaria organizado alrededor de los camélidos con propósitos principalmente de autoconsumo e intercambio campesino no mercantil. ${ }^{13}$

Este desarrollo activa la emergencia de un estrato de campesinos y comerciantes, éstos últimos por lo común foráneos no indígenas, radicados en los valles. Mediaciones económicas se solapan con otras de naturaleza política (administración del Estado, relaciones clientelares) y cultural (castellanización, incorporación de ideologías nacionales y de civilización y progreso) e incorporándose a todas ellas, relaciones de dominio entre un estrato de poder local con sede en las comunidades de valles ${ }^{14}$ y la población tipificada como indígena de las comunidades altoandinas y de las propias comunidades de los valles. Dada la naturaleza corporativa que en ciertos momentos ad-

O sólo puntualmente monetarizado: lo necesario para servir el pago de rentas al Estado o la adquisición de un bien externo valorado, por ejemplo.

14 Compuesto de comerciantes, campesinos acaudalados, pequeños empresarios agrícolas, funcionarios públicos, sacerdotes católicos, todos no indígenas, aunque no necesariamente foráneos. 
quirió ese estrato que dominaba relaciones estratégicas en las microrregiones campesinas, podemos denominarlo como un espacio de dominio privado. El sistema de relaciones al interior de las microrregiones y de éstas con los espacios de articulación externa adquirió por lo tanto una estructura eslabonada: de los núcleos de poder económico y político culturalmente hegemónicos (enclaves salitreros y centros administrativos), hacia las comunidades agrícolas de los valles y, luego de procesadas allí ${ }^{15}$ por una esfera de poder privado, tales relaciones se trasladaban a las comunidades pastoriles de la alta cordillera.

\section{De las microrregiones a la regionalización de las sociedades andinas}

A una estructura de relaciones eslabonadas al interior de las microrregiones y de éstas con los enclaves extractivos y con, más tarde, los núcleos urbanos costeros, correspondió una dinámica de cambio social asincrónica. En efecto, transformaciones de las economías campesinas tendientes hacia la mercantilización y la proletarización de un segmento de la fuerza de trabajo generada en su seno se dan, en general, de manera diferida si comparamos las comunidades bajas respecto de las altoandinas practicantes del pastoralismo. Otro tanto podemos consignar de dimensiones sociológicas y culturales. ${ }^{16}$ Desde finales del S. XIX, entonces, la tendencia hacia una mayor heterogeneidad social resulta de la apertura del segmento de las comunidades agrarias aymaras y atacameñas a la influencia de factorías mineras organizadas en términos capitalistas, las cuales congregaban básicamente población no indígena (criollos chilenos, principalmente, pero también peruanos y bolivianos).

Es de importancia destacar que el diferente dinamismo que ostentan respecto de las comunidades pastoriles no obedece al aislamiento geográfico, sino que al aislamiento social impuesto a estas últimas por la estructura de dominación de la que formaban parte al interior de las microrregiones campesinas. Sostenemos la hipótesis, por lo tanto, de que el modelamiento etnoclasista de las microrregiones durante el S. XIX deja a las comunidades altoandinas como un segmento retardatario en cuanto a los cambios que de manera privilegiada estaban produciéndose en las áreas agrí- colas bajas. Lo son como parte de un sistema de dominación que se estructura con arreglo a divisiones sociales no enteramente coloniales, ni propiamente modernas. Son híbridas a su modo y, en cualquier caso, heterogéneas con respecto de un horizonte de modernidad al que se incorporan y de una tradición colonial desde la que surgen.

La condición social subordinada de "indio"17 a la que quedaban afectos los ganaderos de las comunidades de la alta cordillera asemeja una división social estamentaria de origen colonial. No obstante, es operada por un estrato social con origen en una modernidad que empieza a abrirse paso. Es un poder local reunido bajo la denominación de "peruano" (en Arica y Tarapacá) o "boliviano" (en Atacama) y, ya bien entrado el S. XX, de "chileno". Sus miembros prominentes al parecer estaban penetrados por ideas y visiones de futuro modernizantes (nación, industrialismo, progreso, transformación). Desde el punto de vista de su origen étnico, se trata de un estrato de criollos de la zona y de forasteros, además de algunos miembros de comunidades indígenas que transitaron social y culturalmente desde la condición de campesino indio a la de campesino rico o pequeño empresario no indígena. Durante el S. XIX controlaron el poder microrregional con base en sus propios recursos económicos y en el capital político y simbólico que heredaron o lograron reunir; por ejemplo, resulta estratégicamente privilegiada su posición como mediadores económicos y políticos de los sectores de población "india" hacia fuera de sus microrregiones con la administración republicana y la economía hacendal y capitalista.

15 En el sentido de sometidas a una traducción de códigos sociales y modalidades de poder locales.

16 Por ejemplo, apertura hacia sociabilidades obreras y hacia sistemas ideológicos y simbólicos populares y modernos, lo que a su vez se corresponde con una puesta entre paréntesis -en el sentido de reposicionamiento y pérdida de centralidad- de la capacidad de integración social y simbólica de las comunidades mediante las instituciones comunitarias (como el sistema de cargos, el trabajo colectivo) y la matriz religiosa católico andina (que a este respecto fungía como un ethos unificador).

17 Y, por lo tanto, de campesinos y pastores segregados y contenidos en sus comunidades. 
Queda entonces claro que esos apelativos estigmatizantes acuñados en momentos coloniales no representan más que un uso formal de la tradición, en función de producir y reproducir formas de dominación transicionales. Estas se encuentran representadas, para la región que analizamos, por mediaciones sociales o eslabonamientos de los segmentos sociales campesinos con un sistema regional en el que imperan las fuerzas del mercado y poderes emanados del capital salitrero y, por otra parte, de los campesinos con la administración del Estado republicano.

En una perspectiva histórica de largo plazo, por lo tanto, encontramos un pastoralismo andino que prosigue y cambia diferenciadamente al interior del marco provisto por las microrregiones. Lejos de entenderse como pura continuidad, la persistencia de esta actividad es atribuible, tanto a factores de reproducción internos, como al propio sistema económico y social de microrregiones andinas del S. XIX que resulta del desarrollo de nuevas formas de integración con la región. Esta misma condición histórica en el sentido de contemporánea y determinada, parcialmente al menos, por procesos y sistemas sociales más inclusivos, presidirá la dinámica de la continuidad y el cambio en el pastoralismo aymara y atacameño de la segunda mitad del S. XX. Antes de detallarlos y ponerlos en relación con niveles analíticos más amplios, es necesario caracterizar siquiera brevemente tales procesos y sistemas resultantes.

\subsection{Procesos de integración regional a través del mercado y del Estado}

Resulta cómodo analizar esos procesos considerando dos grandes fuerzas, integradoras por definición: la acción del mercado y la del Estado. En Atacama, Tarapacá y Arica el ciclo minero del salitre en la meseta intermedia y mixto en la cordillera andina (azufre de Tacora y Ollagüe, plata de Choquelimpie y Collahuasi, bórax en algunos salares altoandinos) se deprime drásticamente con la crisis mundial del año 1929. La actividad minera no termina y, en algunos casos puntuales como el del cobre de Chuquicamata, ésta se incrementa, pero claramente disminuye su dinamismo y extensión. Es con relación a los resultados de esa crisis que se ajusta la relación entre campesinado andino y economías capitalistas. Por otra parte, es en el Estado chileno donde queda radicada la cuestión social heredada de la crisis minera del Norte. Este adquirirá un papel de administrador de los efectos sociales negativos heredados de ella, así como la de promotor de iniciativas de redistribución de población, expansión del empleo y fomento industrial. Estos roles se corresponden, desde la década de los años 40 , con la redefinición del modelo de desarrollo ${ }^{18}$ y un sentido de inclusión política y social ampliado. Es también en relación con la acción y con las consecuencias de la acción del Estado desarrollista que la relación entre el campesinado andino y la región se redefine.

Los campesinos atacameños encuentran en el empleo minero provisto por Chuquicamata y en las faenas extractivas de la alta cordillera andina una alternativa a la disminución de la demanda de fuerza de trabajo producida en las factorías salitreras. Hasta hoy seguirán empleándose masivamente en la minería y en los segmentos de fuerza de trabajo asalariada vinculados con la minería. Su papel como productores de forrajes y de bienes de consumo humano (carne y frutas) realizados en el mercado regional no se habrían visto afectados mayormente por la crisis debido a la persistencia de una demanda insatisfecha. ${ }^{19}$ Los problemas surgen cuando entra en operaciones el ferrocarril de Salta a Antofagasta a finales de la década de 1940, tornando prescindible la alfalfa de los oasis y cuando la puesta en funciones de la Carretera Panamericana en la década de los años 60 permite la llegada de alimentos frescos desde el centro y sur del país en cantidades, calidades y costos suficientemente ventajosos para desplazar producciones atacameñas. Las producciones campesinas no se sustraen totalmente del mercado;

De uno extractivo exportador basado en capitales principalmente ingleses, a uno de substitución de importaciones en el cual se otorga un importante protagonismo a los capitales nacionales.

19 Se trata de regiones desérticas en las cuales, faltando medios e infraestructura de transporte adecuados, se hace difícil y de alto costo el abastecimiento oportuno con vegetales, frutas y carne frescos a los centros mineros, pueblos y ciudades. 
rebajan su condición. Pasan de bienes valorados e indispensable a bienes menos demandados, de más bajo costo y consumidos por segmentos populares. Se trata de una crisis tardía de articulación del campesinado andino con el mercado que se resuelve incorporando más población a la fuerza de trabajo asalariada regional e intensificando migraciones. ${ }^{20}$

Los aymaras, por su parte, participan de un proceso parcialmente diferente del que se acaba de describir. Falta en este caso un mercado de fuerza de trabajo minero que posibilitara el desarrollo de una proletarización conectada con la residencia urbana. La crisis salitrera no implicó el cierre de todas las factorías y un centro urbano como Iquique tenía todavía un contingente de población numeroso. De esta manera, trabajadores aymaras de comunidades de valles, especialmente, siguieron presentes en la minería del salitre y diversos productos campesinos (hortalizas, carne, frutas) fluían desde las comunidades hacia los poblados y campamentos del desierto. Aprovechando la red ferrocarrilera, desde allí se redistribuían a sectores del desierto más distantes e incluso hasta los puertos (Iquique y Pisagua). Como en el caso atacameño, el alto costo y la lentitud del abastecimiento de alimentos frescos desde el centro del país mantuvo la demanda y valor pecuniario de productos campesinos de consumo humano. ${ }^{21} \mathrm{El}$ estrechamiento del mercado tradicional de los campesinos por el cierre de cada vez más campamentos salitreros generó el retorno de una parte de la fuerza de trabajo aymara a la agricultura, pero una que no podía allí expandir su producción o mejorar ingresos monetarios con fuentes alternativas. Como mecanismo de descompresión, tempranamente, entonces, se fue dando la migración aymara desde los valles a los centros portuarios. Ya en la década de los años 40 se detecta un cierto

Es el momento en el cual las producciones campesinas se deprecian y, por lo tanto, resulta menos atractivo sostener la vieja fórmula de la segmentación de la fuerza de trabajo campesino en el asalariamiento, temporal por lo común en las economías empresariales y en actividades campesinas rurales. Alternativamente, ahora, se adoptará la residencia urbana y se instrumentarán proyectos de movilidad social a través del asalariamiento definitivo, la educación y el cambio sociocultural. número de migrantes aymaras en las ciudades costeras (González, 1996; Gundermann, 1998). La intensificación posterior tiene dos fuentes: las medidas de fomento económico y el consecuente desarrollo urbano provocados por el Estado (Puerto Libre de Arica, su ulterior industrialización, el fomento pesquero de Iquique) que funcionan como un factor de atracción, y la competencia de otras regiones en el abastecimiento de productos perecibles luego que la Carretera Panamericana abriera al tráfico terrestre el traslado de mercancías desde Perú y el centro de Chile, lo cual resulta un factor de depresión de una agricultura andina ya bastante mercantilizada. ${ }^{22}$ Hasta aquí las similitudes, porque la incorporación urbana es diferente a la atacameña. El asalariamiento definitivo de los migrantes no es central en el caso aymara; sí lo es en cambio la ocupación de nichos de actividad económica en el sector terciario de la economía regional (comercio informal o formal en pequeña escala). En segundo lugar, la agricultura de Arica y Tarapacá (entre ella la andina e indígena) no ha sido desplazada como sí ocurrió en gran medida con la del área atacameña; por el contrario, se ha activado y complejizado, insertándose en mercados de varios tipos. Para las distintas etapas de realización económica de la agricultura agrícola regional la presencia aymara es notoria y, a veces, masiva. En estas condiciones, la relación entre agricultura campesina -ganadería andina incluida-, circulación mercantil de productos y subproductos agropecuarios y consumo tiende a realizarse con una participación activa de aymaras. Sale casi sobrando decir que en el inicio de los ciclos de realización agraria encontramos unidades de producción campesina intensamente mercantilizadas y, por lo tanto, monetarizadas. Nuevamente, la asincronía del proceso de migración es claramente perceptible: la migración masiva desde las comunidades altoandinas se hace

Esos mismos problemas habrían impedido un abastecimiento más integral de frutas y hortalizas desde los valles bajos de Arica (Azapa y Lluta) y el sur del Perú a la zona salitrera interior y a los puertos.

22 No cabe desdeñar en la explicación de las migraciones a varios factores socioculturales: es en los centros urbanos donde se puede aspirar a alcanzar educación (y con ello ascenso social) y a realizar cambio cultural (hacia formas más prestigiosas). Con ello, se posibilita la circulación interclasista (de campesino rural a urbanitas de clase media) y el traspaso de fronteras étnicas (de "indio" a ciudadano "chileno"). 
notoria sólo durante la década de los años 70 , intensificándose en los ' 80 y culminando, al parecer, durante la de los años ' 90 . A riesgo de simplificar en exceso, digamos que el retardo es explicable como un resultado de las relaciones de dominio que funcionaron hasta entrado el S.XX como estructura sociológica de las microrregiones andinas. Factor eficiente en la ruptura de esas formas de dominación fue la intervención desarrollista del Estado en los sectores altoandinos. Son de importancia insoslayable la creación de una red de caminos de penetración desde la carretera Panamericana hacia la zona interior y, con alguna antelación, la formación de una red de escuelas de enseñanza básica. Medios físicos e instrumentos culturales para hacer viable la migración fueron así entregados a una población en varios aspectos históricamente aislada y en gran medida monolingüe. Los cambios en el pastoralismo serán correlativos, entonces, con los cambios en las comunidades altoandinas al abrirse con mayor plenitud su horizonte de referencia hacia la región.

Por tanto, las poblaciones aymaras y atacameñas se regionalizan. No son las microrregiones andinas el espacio objetivo de lo más sustancial de sus mundos de vida y trabajo; ahora lo es la macrorrre-gión norte. No sólo campesinos; también son asalariados, trabajadores por cuenta propia urbanos, pequeños empresarios, etc. Tampoco son sólo rurales; de hecho, son más bien urbanos si atendemos a una inferencia estadística. Difícilmente puede concebírseles como sociedades tradicionales; aunque no se recusa la apelación a la tradición son, ante todo, poblaciones resultantes de procesos de modernización. Los remanentes de formas de dominación neocolonial terminan por disolverse, mientras la elite del poder local desaparece y los dominados pugnan por alcanzar carta de ciudadanía; la dominación ahora se desplaza hacia formas más globales. Lejos se está de los sujetos campesinos e indígenas relativamente unitarios de antaño. Se trata de poblaciones plenamente articuladas a la región norte, visiblemente diferenciadas en un sentido tanto horizontal como vertical e inmersas en escenarios de complejidad social en aumento.

Se trata de una transformación estructural de gran alcance, pero que no se puede confundir con la ruptura de toda práctica social o institución cultural preexistente. Por una parte, se presenta una tupida red de relaciones sociales indígenas ruralurbanas de doble sentido que hace analíticamente de poco interés considerar uno y otro espacio por separado: hay una sociedad indígena regionalizada. Por otra, los lazos sociales principales, antaño fundados en posiciones adscriptivas, hoy se combinan con patrones de interacción basados en criterios electivos; nos encontramos entonces con sociabilidades de doble faz: relaciones sustentadas en solidaridades sociales dadas a los sujetos y por tanto preexistentes a ellos, en especial respecto de grupos y redes internas institucionalizadas, y aquellas producidas con arreglo a elecciones e intereses, principalmente en las relaciones externas. Finalmente, la propia etnogénesis actual corresponde a una forma de subjetividad colectiva cuya producción social no sería posible sin las condiciones sociales creadas en las transformaciones de las últimas décadas, pero al mismo tiempo es una forma de división y clasificación social que procede con base en materiales (memoria histórica, formas de conciencia social, sensibilidades, etc.) provistos por la tradición. El único corolario posible de los ejemplos anteriores, es entender que las maneras de vivir y procesar una modernidad periférica como ésta no se reduce al modelo de la modernización de los países centrales.

\section{Los cambios en el pastoralismo andino}

Es tiempo de volver al pastoralismo andino y a la situación que le es propia en las sociedades indígenas de este último medio siglo. Postulamos más arriba que las transformaciones estructurales de las sociedades indígenas en el S. XIX y en la primera mitad del XX tuvieron consecuencias sobre el pastoralismo andino. Una nueva serie de cambios que hemos denominado como el paso de sociedades estructuradas en microrregiones a sociedades regionalizadas sugeriría, por lo tanto, que el pastoralismo también sufre transformaciones significativas.

Intentemos primero una definición de la nueva situación del pastoralismo a modo de hipótesis de trabajo. La heterogeneidad de las unidades de tenencia $^{23}$ en las comunidades altoandinas se co-

Pocos o muchos animales, de una u otra especie o con composición mixta variable. 
rresponde con una igualmente amplia heterogeneidad de unidades económicas familiares que poseen esos animales,${ }^{24}$ de regímenes laborales para atender su pastoreo ${ }^{25} \mathrm{y}$ de arreglos residenciales. ${ }^{26}$ Resulta evidente que esa heterogeneidad deja al pastoralismo como una entre otras prácticas económicas de sólo una fracción de las unidades de producción familiar que reconocen pertenencia u origen en comunidades altoandinas $y$, con más frecuencia de la esperada, sin que ella tenga ninguna significación en su estructura de ingresos. Esta podría replantearse en términos de la reproducción de derechos a la tierra por parte de migrantes o en términos de valores culturales. Pero, nuevamente aquí no resulta clara su importancia. En un caso porque los derechos de acceso a la tierra se detentan mejor con base en títulos legales más que en el puro reconocimiento social $y$, en el otro, porque la diversidad social imperante se relaciona también con una considerable heterogeneidad cultural interna, en la cual tampoco escasea el rechazo a diversos aspectos de la matriz tradicional (códigos, simbolismos, representaciones, valores, etc.).

Desde luego, no es el término del pastoralismo andino. Con lo dicho no se quiere vaticinar su más o menos pronta desaparición o su disolución como práctica andina reconocible en cuanto que tal. Se quiere precisar, no obstante, que como cualquier práctica social está propensa a cambios históricos y que en el período que aquí analizamos esos cambios la dirigen con rapidez hacia una actividad de importancia económica y social secundaria.

\subsection{Economías campesinas, sociedad aymara y pastoralismo hoy en la región andina}

La crianza de camélidos domésticos y ovinos en condiciones campesinas es todavía, como se lleva dicho, una actividad exclusivamente andina en el norte de Chile. La evolución seguida por el pastoralismo es diferente, sin embargo, según si evaluamos la zona aymara o la atacameña. Es prudente entonces una presentación separada de tales avatares.

Las economías campesinas aymaras y los sistemas de relaciones sociales andinas están sujetas a considerables presiones de cambio durante el último medio siglo. Como resultado de ello, la eco- nomía se diversifica y los antaño sólo o principalmente productores agropecuarios empiezan de manera cada vez más extendida a incorporar salarios temporales rurales o urbanos, ingresos provenientes de actividades comerciales, ingresos obtenidos del transporte por quienes tuvieron capacidad de acumulación, retornos monetarios por concepto de otros trabajos por cuenta propia (producción y comercialización de artesanías, por ejemplo), muchos perciben subsidios del Estado, uno que otro obtiene rentas, etc. Por esta vía de cambio las economías andinas se hacen crecientemente mercantilizadas y monetarizadas. En efecto, la apertura de los patrones de consumo a los bienes externos e industriales, posibilitado por la existencia de ingresos monetarios, refuerza la necesidad de esos mismos ingresos en los mercados de fuerza de trabajo, en los de productos campesinos y en las varias modalidades de trabajo por cuenta propia. Esa misma tendencia se aprecia en el destino del gasto y el ahorro más allá de las necesidades de subsistencia vital, cuando ello es posible: este se dirige a costear servicios (educación), bienes urbanos (vivienda) y/o a generar capital de trabajo (comercial, por ejemplo) o adquirir medios de trabajo (chacras o un vehículo de carga) con los cuales insertarse de mejor manera en ciertos mercados regionales.

Al mismo tiempo, numerosas economías familiares aymaras se descampesinizan y desruralizan, parcialmente o en su totalidad: con bastante fre-

Desde aquellas que dependen exclusivamente de la producción generada en la explotación ganadera, hasta aquellas que mantienen un par de animales con parientes y que en cualquier momento podrían terminar por consumir o vender, pues esa tenencia no representa económicamente nada.

25 En un extremo, propietarios ausentes cuyos animales pastorean peones o medieros (caso de rebaños de cierta importancia) o que se encuentran al cuidado de familiares (caso de rebaños pequeños o de unas pocas cabezas), y, en el otro, unidades que cubren el pastoreo enteramente con su propia fuerza de trabajo; la gama de situaciones intermedias es bastante rica.

26 Residentes permanentes en valles agrícolas o centros urbanos, residentes de temporada en las estancias ganaderas durante los meses en los cuales el ganado demanda mayor atención (noviembre a marzo), unidades residencialmente fragmentadas, unidades residentes permanentes en estancias ganaderas, etc. 
cuencia una unidad económica cuyo origen es una comunidad ganadera altoandina mantiene actividades económicas en el sector de origen, en valles agrícolas y/o en las ciudades costeras; puede que allí algunos dejen de ser una economía pobre para saltar a la condición de un micro o pequeño empresario o trabajador por cuenta propia capitalizado. Una cierta proporción ha dejado el pastoralismo y se instala en los valles agrícolas y muchos otros se han incorporado con plenitud a los espacios urbanos. Por tanto, junto con diversificarse las economías aymaras, también se redistribuyen espacialmente. Resulta, sin embargo, que aun cuando no permanezcan nexos económicos, es difícil que éstos también falten en la esfera de las solidaridades parentales y en el de la identificación con el terruño de origen. Economía, vínculos de parentesco, vecindad y amistad, identificaciones religiosas y con el espacio originario definen una nutrida red de relaciones sociales entre individuos, unidades familiares, segmentos y grupos rurales y urbanos que dan origen a lo que en otro lugar hemos denominado comunidades translo-calizadas (Gundermann, op. cit.).

Con una más profunda mercantilización de las economías aymaras el pastoralismo termina de salir de los marcos microrregionales en los que se desenvolvía. ${ }^{27}$ Lana y fibra se transan regularmente en ferias fronterizas con destino a Perú y Bolivia; cueros de ovinos y camélidos han tenido ciclos de demanda; la carne de llama y alpaca se expende regularmente en puestos de venta urbanos de Arica, Pozo Almonte e Iquique. Sus consumidores son la ya numerosa población andina radicada en las ciudades, pero también segmentos populares no indígenas que ven en estos productos una alternativa de mantener a bajo costo el consumo de proteína animal. ${ }^{28}$ La demanda de reproductores dirigida al mercado internacional de pets, centros experimentales pecuarios y universidades requirió, a finales de la década de los años 80, la aplicación de medidas administrativas para contener una presión indiscriminada sobre los rebaños. Las artesanías textiles dejaron en gran medida de autoconsumirse y ahora se elaboran más bien productos destinados al mercado de las artesanías. Se ha creado en definitiva un mercado bastante variado para produc- tos y subproductos pecuarios originados en el pastoralismo andino. La ganadería altoandina sirve hoy, primordialmente, una demanda de mercados regionales, nacionales y aun internacionales; el autoconsumo ciertamente no ha desaparecido pero se ha limitado, mientras el intercambio complementario es ya historia pasada. ${ }^{29}$

La articulación del pastoralismo con el mercado y la transformación de las economías campesinas y de la propia sociedad aymara (diferenciación horizontal y vertical, descampesinización, desruralización, regionalización) posiciona la ganadería aymara de una muy distinta manera al interior de la sociedad indígena. Aquella es hoy algo muy diferente de antaño. Sin duda que para un segmento de las unidades domésticas residentes en comunidades que practican pastoralismo este sigue siendo el principal medio de costear la subsistencia,

27 Debe recordarse que un mercado de lana de camélidos se desarrolló en el sur del Perú ya durante la primera mitad del S.XIX. A esos y a otros que se activan desde Iquique y Arica, posteriormente, estuvieron relacionados los ganaderos aymaras que analizamos. Al realizarse principalmente como intercambio por productos industriales o de otras ecologías andinas, la monetarización fue todavía débil, pero la mercantilización es indudable. Por otra parte, partidas de ovinos fueron con frecuencia adquiridas a ganaderos de las comunidades por parte de comerciantes intermediarios afincados en los valles para su ulterior consumo en las factorías mineras. El charqui (carne seca y salada) de llamas tampoco fue desconocido entre los trabajadores de los enclaves mineros.

28 Iniciado primero en forma clandestina por población andina migrada a las ciudades costeras a inicios de los años '80, en plena recesión de la economía chilena, el consumo de carne de llama y alpaca rápidamente se extiende a otros sectores. La incapacidad de la masa regional de responder al rápido desarrollo de la demanda urbana estimuló un activo contrabando desde regiones bolivianas vecinas. Temimos algunos interesados en el tema que un aumento explosivo del consumo y los relativamente atractivos precios que el producto alcanzó pondría en peligro la masa camélida regional; el contrabando actuó como un efectivo contrapeso.

29 En realidad, lo era ya a inicios de la década de 1980 cuando en Isluga, uno de los sectores que ostentaría una economía de corte tradicional mejor conservada, no incorporaba el intercambio de productos y subproductos con los valles más que en un $8 \%$, aproximadamente, de la circulación total de mercancías por ciclo anual (incluido autoconsumo). 
continúa siendo un ámbito de trabajo central y todo ello gravita con fuerza dando identidad económica y sentido de vida a sus cultores. Se trata, en cualquier caso, de un segmento minoritario del total de la población originada y todavía relacionada con las unidades territoriales (comunidades sucesoriales, comunidades pueblerinas) de origen. Además, debe repararse de inmediato que aquellos están representados por parejas de ancianos o ancianos solos o por unidades que poseen rebaños económicamente viables, los cuales, por falta de oportunidades, reserva ante los riesgos implicados, fracasos migracionales o inadaptación a la vida urbana y de los valles y/o identificación con el terruño, etc., han desestimado la migración.

No obstante, de una u otra manera todos ellos están involucrados en fenómenos económicos de deslocalización. Algunos se encuentran implicados directamente en tales hechos. Los principales son la educación de los hijos en lugares distintos y distantes (centros escolares rurales y urbanos), de donde muy probablemente no retornarán a la vida pastoralista; otra modalidad es la inversión patrimonial, principalmente de casas urbanas aprovechando las franquicias estatales (subsidios) para adquirir viviendas urbanas populares, con las cuales además suele apoyarse la instalación urbana de hijos estudiantes o que migran, inversiones que a veces también generan algún tipo de rentas; finalmente, en esta línea cabe citar lo que genéricamente podríamos denominar como herencias anticipadas. Ellas son entregadas usualmente en forma de animales que, contra lo que fue tradicionalmente usado, dejan de ser un complemento significativo de la instalación viable de unidades económicas campesinas autónomas, para dirigirse ahora a hacer posible el desarrollo de unidades económicas no campesinas o parcialmente campesinas; por ejemplo, liquidando ganado propio y entregado por los progenitores para la adquisición de una chacra en los valles agrícolas, en función de disponer de capital de trabajo para la aparcería agrícola o para dar inicio a actividades comerciales, constituir la base de la adquisición de un medio de transporte rentado, etc.

Indirectamente, esas unidades son por lo común cuidadoras de animales de parientes cercanos y, ocasionalmente, aparceros de vecinos y amigos que no han renunciado a mantener la explotación ganadera en las tierras altas a pesar de residir afuera. Aun para aquellos que mantienen sus animales sujetos a una vigilancia periódica directa mediante viajes regulares, la presencia de los residentes asegura una vigilancia general útil para evitar hurtos, evitar la intromisión de ganaderos de comunidades vecinas o dar aviso sobre irregularidades en el rebaño.

Tales formas directas e indirectas de participación de unidades con presencia más o menos permanente de todos o una parte de sus miembros en las estancias ganaderas ligadas a la diferenciación horizontal y la desruralización aymara, nos ponen en otra dirección del estudio del tema. Un análisis de la decreciente importancia económica del ganado para la población aymara ligada a comunidades de origen donde se practica pastoralismo debe complementarse con una indagación de la importancia económica estratégica jugada por la ganadería en los procesos que inciden sobre los ciclos de desarrollo de las unidades domésticas. Es una situación paradojal: la escasa relevancia económica del ganado hoy para los aymaras no puede ocultar que ese mismo hecho ha sido favorecido por el empleo estratégico de las existencias ganaderas del pasado en el financiamiento de la migración y las inversiones no campesinas. Salvo el apoyo estatal no hay, básicamente, reinversión campesina en ganadería andina. Este es un recurso que en la perspectiva de los individuos y las unidades domésticas ha servido y sirve para la reproducción económica, pero también para la producción del cambio social. Estamos en presencia, entonces, de un recurso de importancia en las trayectorias de vida de los individuos y en los ciclos de desarrollo de las unidades domésticas: no en pocas ocasiones es lo que ha permitido un giro importante en los cursos de vida individuales y de los hogares. Esos giros se orientan, como llevamos dicho, en dirección de la deslocalización, desruralización, descampesinización, diferenciación, etc., apuntando todos a la recomposición de un nuevo sistema social aymara regionalizado. Por lo tanto, la ganadería altoandina hoy es otra cosa muy distinta que antaño: es un recurso de migración, un capital o recurso de seguridad cuando se mantienen existencias, una fuente complementaria de ingresos y nada más para la gran mayoría de los implicados. 
La regionalización de las comunidades altoandinas sustrae fuerza de trabajo desde la población ganadera residente para dirigirlas al asalariamiento y al trabajo por cuenta propia no campesino. La importancia otorgada a la escolarización de los niños y la educación de los jóvenes y su envío a centros escolares fuera de las áreas de pastoreo tiene un efecto similar. Niños, jóvenes y adultos jóvenes, a veces mujeres que van detrás de los niños para su atención, escasean en el trabajo de los ganaderos altoandinos de hoy. Todo ello condiciona que algunas unidades domésticas dejen de practicar el pastoralismo cuando al mismo tiempo migran y transforman su base económica y de ingresos, en tanto que otras optan de manera diferente y logran instrumentar arreglos para mantenerse siquiera parcialmente como ganaderos. Diferenciación económica y fenómenos de movilidad socioétnica se conectan directamente con los cambios en el pastoralismo. Las implicaciones sobre la tecnología del pastoreo son obvias: esta se ha modificado visiblemente. Lo ha hecho en términos de un notorio empobrecimiento de la atención y prolijidad dada a las actividades pastoralistas de conducción, vigilancia y labores culturales. Menor disponibilidad de pastores implica una vigilancia más laxa y menos eficiente; de este modo aumenta la predación (especialmente de crías por zorros, cóndores y a veces pumas que además atacan a los animales adultos), y los accidentes (por ejemplo, ahogamiento en zonas pantanosas, congelamiento de individuos débiles). Esa misma limitación lleva a perder un manejo más cuidadoso de la distribución de los animales sobre el territorio de las comunidades. En efecto, la tecnología del pastoralismo andino se sustenta en un detallado conocimiento de las disponibilidades y oportunidad de las existencias forrajeras y su compatibilidad con los hábitos de las distintas especies de animales que se posea; todo ello, además, compatibilizándolo con el uso que de la misma pradera realizan otras unidades con sus rebaños. Dadas las condiciones básicas, el éxito del pastoreo se sustentaba entonces en las estrategias particulares diseñadas para una ocupación oportuna de las mejores fuentes de alimentación coordinadas tácita o explícitamente con otros ganaderos cuyas estrategias convergen en un cierto número de lugares. De este modo, podemos asumir que, manteniéndose la necesidad de una organización social del uso particular de las praderas comunitarias, las complejas estrategias del pasado no pueden realizarse plenamente, precisamente debido a la carencia de fuerza de trabajo que pueda atender, sobre todo, aquellas situaciones de rebaños mixtos de cierto tamaño.

Lo anterior se estaría traduciendo en un menor éxito productivo debido a un aumento de la pérdida de animales por predación o accidentes, una mayor frecuencia de pérdida de crías y un desarrollo más tardío de los individuos. Es posible, asimismo, que la composición de los rebaños esté variando ya que regímenes de pastoreo más laxos son posibles con especies poco exigentes. Este no es el caso de los ovinos, provistos de una adaptación comparativamente menos exitosa que los camélidos sudamericanos, y de la alpaca, más especializada, menos rústica y adaptable que la llama. Digamos, a título de ejemplo, que situaciones de control de animales mediante visitas periódicas desde sitios de migración son posibles sólo en el caso de las llamas. Habría, por lo tanto, una transformación en la composición de la masa en términos de una menor diversidad; esta no se verifica, sin embargo, en números absolutos donde desde hace décadas permanece, a pesar de todo, un volumen más o menos constante de animales en la zona altoandina. ${ }^{30}$

Los cambios tecnológicos en el pastoralismo andino tienen también otra fuente. Estos se basan en el término del complejo tecnológico del transporte de cargas y personas con animales. Ellos son además convergentes en varios puntos con las consecuencias que advertimos para los factores analizados del cambio en la sociedad andina. ${ }^{31} \mathrm{Bu}-$ rros, mulas y llamas cargueras componían la base de un sistema de transporte empleado principalmente en el traslado de cargas y personas hacia y desde los valles occidentales a partir de los sitios

30 Este es un dato de importancia en apoyo de nuestra tesis de la continuidad transformada del pastoralismo andino en una sociedad indígena regionalizada.

31 A saber, un cambio en la división social del trabajo andino, en primer lugar regional a través del proceso de diferenciación social horizontal y vertical de la sociedad andina y, en segundo lugar, al interior de ésta, en la división del trabajo doméstico, el cual se complejiza, hacia el asalariamiento y el trabajo por cuenta propia urbano o rural no altiplánico, y se redefine al sustraer la fuerza de trabajo infantil del pastoreo. 
de origen ubicados en la alta cordillera y el borde cordillerano que, más allá de la divisoria de aguas, empalma con las comunidades de la altiplanicie ya en territorio boliviano. La apertura de caminos y el desarrollo del transporte motorizado durante las últimas tres décadas son los principales responsables del término del transporte mediante el empleo de animales. Los caminos interiores se están abriendo hacia mediados de la década de los años ' 60 y, ya a inicios de los '70, prácticamente toda la zona interior se encontraba conectada por caminos en los que podían transitar vehículos motorizados. Este logro es necesario, pero no suficiente para el recambio completo del arrieraje. Se requirieron todavía otros componentes: la formación de un núcleo de transportistas y el acceso de los campesinos a vehículos propios.

Una y otra condición complementaria se alcanzaron cuando, a inicios del período autoritario ${ }^{32}$ se desestimó un desarrollo basado en la industrialización de la ciudad de Arica (ligado al mercado subregional creado por los acuerdos del Pacto Andino) y se creó un polo comercial e industrial en la ciudad de Iquique. Esta no se desarrolló industrialmente, pero ya a los pocos años de entrada en vigencia de la Zona Franca de Iquique (ZOFRI), se inició a través de caminos interiores el transporte de cargas y mercancías hacia Bolivia. Paralelamente, una tasa de cambio del dólar muy baja que favorecía las importaciones, ligado a un desarrollo de la monetarización de la economía campesina altoandina generó una oferta de vehículos baratos adquiribles al amparo de las franquicias de la Zona Franca por medio de recursos monetarios generados de la venta de productos y subproductos pecuarios (carne, cueros, lana, artesanías, etc.) propios o traídos de contrabando desde Bolivia. De esta manera, un cierto número de campesinos del altiplano y de los valles logra hacerse de medios de transporte propios para usos particulares o, con frecuencia, para el transporte y comercio de cargas y pasajeros. Se forman, asimismo, ferias fronterizas destinadas al abastecimiento y comercio en pequeña escala entre campesinos, pero que son aprovechados para potenciar intercambios mercantiles netos. El régimen militar, interesado en la integración de esas zonas interiores fronterizas aisladas, impulsa decididamente el desarrollo de comunicaciones y el mejoramiento de la red terrestre. Ello tiene un impacto bajo la forma de un aumento de las actividades no agropecuarias (comercio y transporte), expansión del sistema de abastecimiento (realizado ahora mediante transporte motorizado) y ampliación del patrón de consumo (menos autorrealizado en circuitos campesinos y, por lo tanto, cada vez más industrial).

Se potencia de esa manera el desarrollo de un nuevo sistema de transporte, de un estrato de comerciantes y transportistas de origen campesino, originado bajo las condiciones descritas. Ellas se suman a un grupo análogo, pero mucho más restringido, que se había ido formando con antelación a la sombra de un comercio y contrabando fronterizo que primero se realizó con animales, pero que ya a finales de los años sesenta empezó a efectuarse por medio de camiones. Esta actividad tuvo inicialmente a comerciantes no aymaras instalados en ciertos valles andinos como sus principales agentes, mientras arrieros indígenas eran los instrumentos eficientes de la ida y venida de mercancías desde las factorías de la pampa salitrera (licores, telas, etc.) y desde Bolivia (hoja de coca, animales, lana de camélidos y ovinos). Posteriormente, con la industrialización del puerto de Arica la cobertura de las mercancías llevadas a Bolivia se amplió para incluir, como uno de sus rubros más destacados, a productos electrónicos. Asimismo, ya a finales de la década de los años sesenta aparecen los primeros campesinos comerciantes sujetos a tutelas que ahora se articulan directamente desde las ciudades de la costa. ${ }^{33}$

Desaparecen las últimas mulas, los burros se venden para fábricas de embutidos y comida de animales domésticos, los machos cargueros de llama son la base para el pago de vehículos motorizados. En una progresión ininterrumpida, iniciada casi una década antes, ya a mediados de los años 80 había desaparecido el arrieraje (de mulas y burros) y el caravaneo (con "tropas" de llamas) como un fenómeno visible, el intercambio complementario se hace despreciable y son eliminados los animales con los cuales se desarrollaban. Todo un componente de gran envergadura del pastoralismo desaparece: a la tecnología del arrieración y análisis pormenorizado. 
je y caravaneo se agrega la desaparición de la producción interna de las llamas cargueras; con ello se toca el corazón del pastoralismo andino. En efecto, las mulas eran adquiridas o intercambiadas (provenían del noroeste argentino) y los burros autoproducidos o capturados de manadas silvestres, pero en ambos casos se trata de unos pocos animales por unidad doméstica, cuya obtención puede implicar desembolsos considerables en el caso de las mulas, pero que prácticamente no tocan el pastoralismo andino. Diferente es el caso de las llamas machos cargueros; su producción se acompañaba de toda una organización e institucionalización interna socioespacial, laboral productiva y cultural.

Era necesario segmentar el espacio pastoril comunitario en a lo menos dos secciones. Un sector más aislado y con praderas más pobres quedaba reservado a los machos cargueros. Estos eran también machos reproductores. Se los aislaba del sector en el cual pastoreaban los rebaños de hembras, crías e individuos jóvenes, más amplio y con mejores pasturas, para evitar, particularmente durante los meses de celo (en la temporada cálida y húmeda de diciembre a marzo), la muerte de crías y hembras por parte de grupos de machos belicosos que buscaban aparearse. El espacio comunitario resultaba subdividido así en un sector de machos utilizado por todas las unidades para dejar y contener allí sus propios cargueros-reproductores, y uno para rebaños de hembras de llamas y sus vástagos en los que además se pastoreaban ovejas y alpacas. Sin machos cargueros la organización del uso del espacio comunitario se modifica: pasa de un espacio dualizado, al interior del cual las unidades organizaban la distribución diaria y estacional de los rebaños, a un espacio único en el cual se reconocen zonificaciones y circuitos flexibles, por lo demás ampliamente traslapados, utilizados por los rebaños de las unidades domésticas de la comunidad. En lo sucesivo no se conservará machos; estos son oportunamente castrados y apenas llegan al estado adulto son vendidos. No se dispondrá en lo sucesivo de grupos de machos para el empadre dirigido. ${ }^{34}$ El pastoreo mismo se simplifica: la atención de los sectores de "machaje", tradicionalmente a cargo de los hombres, desaparece de sus preocupaciones y quebraderos de cabeza. Se bajan de la mula, por así decirlo, para subirse a camionetas y camiones arriba de los cua- les migrar o realizar transporte y comercio. El espacio ganadero se feminiza, además, porque el cambio en los medios de articulación zonal y regional por vía del mercado que afecta a los hombres, se acompaña de una arremetida desde el Estado -y seguida por las familias- para enviar niños y adolescentes a la escuela, muchas veces a internados de concentración escolar. La simplificación del pastoreo y la feminización de esas labores conecta entonces con la transformación de una sociedad aymara altoandina en proceso de regionalización. Los aspectos culturales del cambio tampoco están ausentes.

La vida social rural en la alta cordillera ha cambiado. Los pobladores rurales comparten cada vez más sus oficios campesinos con otros trabajos y actividades por cuenta propia o como asalariados. Asimismo, una alta movilidad de los individuos se asocia a las articulaciones que mantienen con otros espacios en la gradiente altitudinal. Esta movilidad de personas no es privativa de los residentes rurales altoandinos hacia los valles, el desierto y los puertos costeros; lo es también desde esos espacios hacia las comunidades pastoriles, de manera periódica durante el año, intensificándose durante los meses de vacaciones escolares que concuerdan con un aumento de la demanda de atención de los rebaños. ${ }^{35}$ El patrón sociológico de hoy es el de una sociedad altamente móvil en función de su apertura desde microrregiones más o menos autónomas y comunidades autocontenidas a otros espacios, hasta alcanzar cobertu-

Se trata de una técnica reproductiva destinada a asegurar la gestación coordinada de las hembras para así alcanzar coberturas de fertilización más altas y alumbramientos concentrados en los mejores momentos del año, todo lo cual se materializa en tasas de reproducción más favorables. Su abandono es un costo que se está dispuesto a asumir, en parte porque las orientaciones económicas de la fuerza de trabajo masculina se dirigen hacia otros derroteros, pero en parte también porque el manejo de machos estaba normalmente lleno de problemas y conflictos.

35 Esto es válido en todo tipo de comunidades. La escolarización y la educación secundaria y profesionalizante de los hijos es una meta valorada para la cual se está dispuesto a ingentes esfuerzos. Los arreglos residenciales urbanos y de ajuste en la disposición de la fuerza de trabajo familiar disminuyen durante meses vacacionales que son aprovechados por algunas unidades para intensificar labores agrícolas y pecuarias. 
ras regionales. De esta manera, la vida colectiva de las pequeñas comunidades estructurada por las demandas del pastoralismo andino se ha ampliamente transformado merced de cambios en la organización social interna del pastoralismo que se entienden como una consecuencia de cambios más generales en la sociedad aymara. Al abrir sus intereses con esa amplitud las unidades económicas participan de espacios y esferas más diversificadas $\mathrm{y}$, por lo tanto, la vida interna de las comunidades se hace menos densamente imbricada: los hogares convergen sólo en ciertos tiempos, espacios sociales e intereses y, en tal caso, la comunidad deja de sobredeterminar todos o la mayoría de sus plexos de existencia. Desde este punto de vista, los individuos y hogares ganan libertad y autonomía; pierden no obstante el amparo de un micro universo densamente envolvente de sus existencias y trayectorias vitales.

Una comunidad menos volcada sobre el trabajo campesino es una circunstancia que también tiene consecuencias para las dimensiones simbólicas y las instituciones culturales del pastoralismo. Existe sincronía entre el proceso de las comunidades altoandinas de orientarse hacia fuera y el extendido descuido, abandono, negación, etc. que se detecta en los ritos y las representaciones religiosas referidas al ganado. Ello no se limita a la esfera religiosa del pastoralismo, sino que involucra, de manera más amplia, las significaciones asociadas a la actividad ganadera, al valor otorgado al oficio de ganadero, al conocimiento del medio ambiente pastoralista y las relaciones entre sus componentes. No se trata de adoptar, por cierto, una visión mecánica según la cual a cambios sociales y tecnológicos corresponden otros tantos en una dimensión cultural. En verdad, las transformaciones culturales tienen una dinámica propia y ellos deben en primer lugar situarse en referencia a las transformaciones más generales de las sociedades andinas en esta región, algunas de las cuales, no necesariamente las más importantes, son las que acaecen con el pastoralismo. Una hipótesis a desarrollar indica que la apertura hacia la región supone en el nivel de los individuos y de las unidades económicas una mayor individuación y por lo tanto autonomía. Tal condición los transforma en actores más libres que producen decisiones sobre opciones y cursos de acción en distintos aspectos de sus vidas. El ejercicio de esa autonomía conduce a la heterogeneidad social y económica, ya comentada, pero también a la diferenciación cultural. La conexión cada vez más profunda con las dinámicas de la modernidad tal como estas se expresan en la historia regional no produce, ciertamente, un alineamiento unívoco en el sentido dado por el modelo de modernización prototípico, sino que algo más heteróclito. Coexisten dinámicamente tendencias de secularización con la producción de visiones fundamentalistas étnicas y religiosas, fenómenos de continuidad cultural con reprocesamientos que integran lo ya dado con innovaciones, cultura étnica con cultura de masas.

\subsection{Economías campesinas y pastoralismo hoy en Atacama}

El pastoralismo atacameño manifiesta una tendencia diferente respecto del aymara. De una actividad campesina central que daba unidad, junto con la agricultura, a la acción de las unidades económicas de las comunidades del pie de monte andino que la practicaban, ${ }^{36}$ se pasa a una actividad cuya tendencia de largo plazo es a la desaparición. ${ }^{37}$ En el momento presente, dentro de la he-

Recordemos que los oasis bajos se especializan muy tempranamente en la crianza de otro tipo de animales o en el aprovechamiento directo de sus fuentes forrajeras en transacciones de mercado. En cambio, las comunidades del pie de monte andino, con ganadería andina, lo harán de manera más parcial. A título de ejemplo, digamos que entre la segunda mitad del S.XIX y las primeras décadas del XX parte importante de esos recursos fueron dirigidos el talajeo de mulas de trabajo ocupadas en faenas mineras y de vacunos provenientes de Argentina en tránsito hacia Caracoles, primero, y los campamentos mineros de la pampa salitrera, después. Para momentos tempranos destaca la inclusión atacameña en servicios complementarios (arrieraje, forrajeo de animales, aprovisionamiento de productos agropecuarios) más que en el asalariamiento; por ejemplo, en las explotaciones argentíferas de Caracoles (comunicación personal de José Luis Martínez, a partir de una exploración preliminar del archivo de Caracoles en el Archivo Nacional de Chile), cuestión que más tarde irá revirtiéndose.

37 El mejor síntoma de ello es la intervención del Estado con proyectos de repoblamiento de camélidos. No bastan tales esfuerzos. Aparte de algunos errores de alto costo imputables a la ignorancia (traída de alpacas para áreas en las cuales no hay los humedales suficientes como para que prosperen), no se ha reparado adecuadamente en la ausencia de condiciones sociales necesarias para un repoblamiento que vaya más allá de los gestos simbólicos o el folclorismo. 
terogeneidad económica y social reinante en el medio atacameño, constituye una actividad cada vez menos significativa económica y socialmente. Por lo demás, como se recordará, aquellas nunca fueron comunidades ganaderas exclusivas y esta actividad siempre representó sólo un componente entre otros (agricultura, silvicultura, recolección), de economías campesinas mixtas basalmente agrícolas. En apariencia, los segmentos ganaderos tampoco tuvieron importancia social y política destacada por relación a los núcleos de poder radicados en los oasis agrícolas más importantes. Su importancia cultural, aparentemente, también decae, a juzgar por su poca importancia relativa actual en las representaciones, el simbolismo y los rituales andinos de la zona. No cabría esperar otra fisonomía si se recuerda la condición principalmente agraria que por siglos han mantenido estas comunidades. Teniendo en mente transformaciones del pastoralismo aymara que se desarrollan en un sentido diferente, podemos preguntarnos por la especificidad de la dinámica del pastoralismo atacameño y los factores intervinientes en la trayectoria de esa actividad en el largo plazo.

La hipótesis que seguimos, formulada en sus términos más gruesos, indica que la pauta de transformación de la sociedad atacameña en su conjunto es, al igual que la aymara, la de una regionalización de su sociedad. Hablamos, entonces, de un cambio estructural común. El eje de estructuración económica de aquella se despliega, como se recordará, con base en una expansión de la participación aymara en los ciclos económicos en los que se encuentra implicada su economía, ${ }^{38}$ funciones desde las cuales están expandiendo sus esferas de acción económica (hacia el comercio y transporte no agropecuario). En el caso atacameño esa pauta de regionalización se desarrolla también a través del mercado, pero en el de fuerza de trabajo asalariado y, al interior de éste, en el de la minería regional. Al quedar desconectada la economía campesina con el tipo de mercado a través del cual la economía atacameña preferentemente se regionaliza, las actividades campesinas, entre ellas el pastoralismo andino, adquirirán una posición distinta a la que ocupa entre los aymara. comercialización de productos agropecuarios.
Un dato importante para valorar esta diferencia es la debilidad de la reconversión de la producción campesina atacameña para su inserción a los mercados de potenciales productos campesinos regionales. Después de la crisis de inserción, ${ }^{39}$ descrita más arriba, no se aprecia en el agro atacameño un proceso equivalente al que tiene lugar en la región aymara: la referencia al mercado no se generaliza y profundiza en una medida semejante, las redes de comercialización y distribución con amplia presencia indígena urbana faltan igualmente. Tenemos, por lo tanto, un mercado para productos agrícolas y pecuarios campesinos retraído en sus rubros históricos, restringido en los emergentes $^{40}$ y de baja valoración. El otro elemento clave es el de una oferta de trabajo minero disponible históricamente en la región para la fuerza de trabajo atacameña. Este incluye montos visibles de población atacameña asalariada en faenas extractivas o en servicios complementarios por lo menos desde el último cuarto del siglo XIX en adelante. Al parecer fue poco significativo durante el ciclo argentífero de Caracoles, pero se intensificó durante el salitrero y se prolongó con el cuprífero.

Esa distinta posición del pastoralismo andino en una sociedad indígena regionalizada, como la de la agricultura tradicional en general, arranca de una dualización de la economía atacameña: de una parte, tenemos la participación de muchos de sus miembros en economías empresariales como fuerza de trabajo asalariada y, de otra, encontramos una economía campesina todavía produciendo en rubros importantes bienes cuyo consumo es mayoritariamente interno. Hay, de esta manera, una visible discontinuidad entre agricultura campesina y minería industrial (espacios antaño cubiertos, como se recordará, por la demanda de productos campesinos abastecidos localmente) y entre lo rural y lo urbano (este último simbolizado por la ciudad de Calama y el campamento de Chuquicamata). El proceso aymara, en cambio,

Alfalfa y fruta que pierden mercado, una, y competitividad, la otra.

Salvo la venta de algunos ovinos (en San Pedro y Socaire) y, más recientemente, rubros hortícolas como ajos (en Río Grande), zanahorias (en Chiu-Chiu), flores (en Caspana) y habas (en Socaire). 
se caracteriza por transformaciones con solución de continuidad económica (así como social y cultural) entre lo rural, lo agrícola, lo urbano, el autoconsumo y la inserción en los mercados regionales.

¿Qué es entonces lo agrario hoy en el caso atacameño? Decíamos hace algunos años que la migración desde la agricultura a la minería y del campo a la ciudad fue una respuesta a la crisis histórica de inserción atacameña en el mercado y que el desarrollo de ella creaba nuevas modalidades de relación de los mineros (y de otras inserciones en el asalariamiento) con las comunidades y la agricultura remanente. Según estas modalidades, las funciones de las comunidades atacameñas en la economía regional no son agropecuarias o son sólo marginalmente proveedoras de productos de consumo humano de origen agropecuario. La comunidad atacameña sirve más bien una triple función al interior de la economía regional. Primero, proporciona fuerza de trabajo que se encuentra disponible y que está dispuesta a incorporarse al mercado cuando este lo requiere (función de reserva). Luego, se ha transformado en un espacio de retorno temporal para sortear crisis u oscilaciones del mercado de fuerza de trabajo minero que afecta más sensiblemente a una mano de obra no calificada como la atacameña (función de repliegue). Finalmente, constituye un espacio de retorno de fuerza de trabajo gastada que vuelve al campo para terminar sus días (función de retiro) (Gundermann y González, 1995). La primera es una función declinante, debido a una drástica modificación de las estructuras demográficas de la población ligada a la agricultura, la cual se origina en los procesos migratorios, especialmente de las comunidades históricamente más vinculadas a la minería (por ejemplo, San Pedro de Atacama, Toconao o Chiu-Chiu). La segunda, se hace vigente en la medida que se mantengan relaciones y acceso a medios productivos en las comunidades. No obstante, a medida que los fenómenos de inserción urbana de los migrantes se profundizan esas relaciones y acceso se transforman, debido a lo cual esa función mantiene plena vigencia sólo para el caso del segmento de migrantes recientes. La tercera parece ir en aumento debido a que su implementación no depende sustancialmente de la agricultura, sino de jubilaciones y pensiones, del bajo costo relativo de la vida rural y del desarrollo de las comunicaciones y servicios en las aldeas y pueblos rurales, todo lo cual aumenta su atractivo.

Por otra parte, las economías campesinas atacameñas operantes se estructuran de tal manera que la agricultura y crianza de animales es sólo un componente de ellas, más que todo interno, y, con frecuencia, no el más importante en términos de la cuantía de los ingresos reportados (incluyendo comercialización y autoconsumo). Interno porque son producciones dirigidas en un alto porcentaje al autoconsumo y, por lo tanto, sólo parcialmente son objeto de transacciones en el mercado más allá de las localidades rurales. Directa o indirectamente los otros componentes de estas economías se asocian a mercados de fuerza de trabajo regional, como ya llevamos dicho. En suma, la agricultura tiene alguna importancia para un segmento de la población atacameña, pero aún en este caso es visiblemente dependiente de la articulación que las economías campesinas mantienen con las empresariales. Entonces, parcialmente en éste, y más decididamente en otros posicionamientos de la población atacameña en la estructura laboral y de clase regional, el componente campesino es definitivamente una función de la economía empresarial.

De esta manera, la dinámica de las comunidades atacameñas definida en términos de su translocalización consiste en el paso de sistemas locales de productores campesinos a sistemas sociales de origen local, pero translocalizados y proletarizados. Señalamos translocalizado porque la dualización (como atributo diferenciador respecto de los fenómenos de regionalización aymara), es real pero no absoluta, tanto en el ámbito económico del mercado de productos campesinos, como en el de fuerza de trabajo asalariada. Aquí el campesinado atacameño (una minoría, cierto es, de la población total de la etnia) incorpora de manera regular la venta de fuerza de trabajo para balancear su estructura de ingresos. En una esfera sociológica, las relaciones de parentesco establecen una red de vínculos rurales, urbanos y rural-urbanos, aunque posiblemente menos densos que en el caso aymara. En una dimensión cultural es notable la persistencia, como entre los aymaras, de las identidades localistas y de las identificaciones 
con el lugar de origen y los santos locales. De no existir tales puentes rurales -urbanos, campesino- proletarios no se podría, por cierto, hablar de translocalización. Señalamos también proletarización porque este último adjetivo marca la especificidad de la regionalización atacameña. El análisis de los cambios en el pastoralismo andino atacameño precisa de esta consideración para ser adecuadamente valorados.

Pasemos rápida revista a estas transformaciones. Como en el análisis del pastoralismo aymara, fijaremos nuestra atención en las unidades domésticas y en los cambios en la división social del trabajo interno, para luego abordar los cambios tecnológicos y los culturales. Partamos recordando que se trata de comunidades con orientaciones productivas mixtas, que en muchos casos la crianza de animales no es importante para las unidades económicas campesinas y que históricamente el pastoralismo sufrió transformaciones de importancia en varias de ellas. En efecto, los oasis bajos, a la vez las comunidades más importantes de la zona, como San Pedro y Chiu-Chiu, no incluyen pastoralismo andino desde mediados de siglo, aproximadamente. Su vigencia se restringe a las comunidades de la vertiente andina (Talabre, Socaire, Ayquina, Caspana, Toconce y Machuca son las más importantes). En el primer caso, los cambios en las economías campesinas (mercantilización, monetarización, asalariamiento, etc.) explican el retroceso del pastoralismo. En el segundo, fenómenos análogos aunque desarrollados con cierto retardo y menor intensidad inicial se suman a la enajenación y destrucción de fuentes forrajeras tradicionales realizadas por empresas mineras y de producción de agua potable en favor del abastecimiento hídrico urbano y minero (Alto Loa y Toconce, principalmente). Todo ello, a su vez, se desenvuelve en el marco de un panorama ambiental de intensificación de la desecación.

Las unidades de producción campesinas atacameñas están involucradas en fenómenos de regionalización y translocalización inaugurados por las migraciones temporales y definitivas hacia centros mineros y núcleos urbanos dependientes de la minería regional. ${ }^{41}$ A diferencia de procesos semejantes que han tenido lugar en las comunidades aymaras, en las atacameñas los recursos pecuarios, entre ellos los disponibles a partir del pas- toralismo andino, tienen una importancia más modesta en la deslocalización, diferenciación horizontal o vertical y la desruralización. Cuando se posee animales éstos ciertamente pueden emplearse en el financiamiento de la migración, en costear la educación de los hijos o en engrosar fondos destinados a una inversión patrimonial urbana. No obstante, dado que un pastoralismo andino que incluya crianza de camélidos tiene menos posibilidades de realización mercantil (salvo quizá la fibra de llama), productos y subproductos circulan y se consumen preferentemente en un nivel local sin transacciones monetarias constantes y, por lo tanto, el aporte que tales producciones pueden hacer a empresas de externalización de las economías campesinas se reduce proporcionalmente. En dos palabras: el pastoralismo andino retiene durante las últimas décadas una participación pobre en la regionalización de la sociedad atacameña. Siendo esto así, la presencia de hechos asociados característicos de la dinámica aymara no se encuentran presentes de manera visible o con parecida intensidad en la realidad atacameña. Por ejemplo, el uso del ganado como patrimonio para la instalación de nuevas unidades domésticas o como fondo para la inversión económica con el cual dar inicio a fenómenos de diferenciación social; hablamos también de los complejos arreglos sociales y laborales a los que da lugar la mantención de la actividad pastoralista andina por parte de unidades migrantes.

Aunque con una participación débil en cuanto factor asociado a la externalización, ésta, una vez producida, acarrea impactos duraderos sobre el pastoralismo andino. Visto en términos del trabajo ganadero, una fuerza de trabajo masculina crecientemente orientada al trabajo asalariado regional y una infantil sustraída del apoyo que en el pasado brindaba a las labores domésticas, no sólo feminiza $^{42}$ el pastoralismo, sino que lo degrada.

Excepcionalmente, hacia microcentros de servicios, vocación que va adquiriendo San Pedro en la actualidad; se trata de un fenómeno activado por el explosivo desarrollo del turismo hacia esa localidad y alrededores durante la última década y media.

42 De Cupo, una comunidad cercana a Ayquina, reportajes periodísticos hablaron años atrás como de un pueblo de mujeres. 
El trabajo asalariado atacameño conlleva un disciplinamiento de la fuerza de trabajo y restricciones en la organización de actividades complementarias muy diferente al ideal de trabajo por cuenta propia aymara. El trabajo en la minería implica, asimismo, una identidad laboral definida e identificaciones fuertes que proveen disposiciones de acción mucho más exclusivas que las que denota la labilidad aymara. Por todo ello, la flexibilidad para la asignación de la fuerza de trabajo de los hogares y la disposición a mantener actividades campesinas es de naturaleza muy diferente entre las comunidades translocalizadas atacameñas y las aymaras. Cuando, como en la situación atacameña, las actividades tradicionales no son posibles de mantener, éstas tienden con más facilidad a retroceder y eventualmente a desaparecer. Este habría sido el caso del pastoralismo andino atacameño.

Son diversas las repercusiones tecnológicas originadas en la sustracción sistemática de fuerza de trabajo desde el trabajo ganadero. Primero, sujetas a menor disposición de fuerza de trabajo las unidades pastoralistas deben procesar mayores obstáculos para el desarrollo de estrategias de movilidad y trashumancia elaboradas. Si lo anterior es cierto, también lo es respecto al deterioro de la calidad de las labores de conducción y vigilancia cotidianas. Tercero, la integración vial de la zona atacameña dejó en desuso al arrieraje y al caravaneo con llamas cargueras y, con ello, la desaparición del machaje fue sólo cuestión de tiempo. ${ }^{43}$ Recordemos que el machaje requería fuerza de trabajo masculina que con la integración estaba dirigiéndose aceleradamente hacia el trabajo asalariado en las empresas mineras de la zona. Cuarto, al desaparecer las llamas machos cargueros-reproductores, las técnicas de manejo reproductivo se deterioran y se hacen menos eficientes; la productividad de los rebaños disminuye. Quinto, si consideramos, por otra parte, que la complejidad y variedad de las modalidades de manejo ganadero es una función de la seguridad productiva y que a ello obedece en definitiva la diversidad de estrategias y la elaboración que algunas de ellas manifiestan, el retiro de la fuerza de trabajo masculina e infantil de las actividades campesinas actúa en contra del sostenimiento de esa misma variedad y complejidad; se impone su simplificación como se explicara para fenómenos aymaras equi- valentes, aunque con manifestaciones menos agudas.

En otro sentido, el aumento de la aridez ambiental en una zona extrema como la de la cordillera andina atacameña presionaría por un arco amplio de estrategias, algunas de las cuales revestirán alta complejidad; sin embargo, ello ya no resulta factible cuando las condiciones sociales se extreman, ni fácil o conveniente de implementar en aquellos casos en que sería posible dar continuidad material al pastoralismo. En la primera situación, la opción es el retiro; es decir, el abandono de la ganadería y muchas veces también de la agricultura en favor de modalidades alternativas de trabajo y vida. El segundo nos lleva por el camino del cambio hacia modalidades de crianza que se acercan a los fronteras de salida del pastoralismo andino (acudiendo al uso de praderas artificiales de alfalfa para alimentar camélidos, por ejemplo); no obstante, esta solución también queda vedada en favor de una crianza de ovinos para el mercado con los cuales ganar liquidez monetaria indispensable para satisfacer una pauta de consumo humano penetrada íntimamente por los bienes industriales.

La discontinuidad entre mercado y agricultura campesina, entre migrantes y productores campesinos confabula también para que las redes sociales de las comunidades translocales atacameñas sean menos nutridas y, en relación con el pastoralismo, existan dificultades mayores para articularlas en función de la tenencia de animales por los migrantes. Las comunidades regionalizadas son fuertes socialmente mediante vínculos de amistad y parentesco, pero de ello no deriva, automáticamente, una capacidad para su empleo directo y extendido en las complejas formas de solidaridad y acuerdos laborales agropecuarios del tipo como los que se dan entre los aymaras.

Esa misma fuerza está presente en dimensiones culturales, pero de ella tampoco se derivan implicaciones favorables para el pastoralismo andino. En efecto, la religiosidad andina bajo su formato catolicista es una poderosa fuerza de unidad

Para la zona atacameña, esta práctica ha sido constatada en el caso de la comunidad de Toconce. 
materializada en las congregaciones rituales (Carnavales, Santos Patronos), pero que sólo tangencialmente incluye alguna referencia al pastoralismo; falta en gran medida el sistema ritual andino donde las ceremonias ganaderas tenían un lugar destacado. Lo anterior no es raro, si se repara en que esta última ritualidad es para los atacameños una manifestación extraña a ellos, de "coyas", de "indios", con los cuales expresamente no querían confundirse. El propio pastoralismo andino gozaba de un bajo prestigio como un oficio campesino. Por lo demás, fronteras locales y étnicas se trazaban en las identidades colectivas con el pastoralismo como actividad distintiva del "indio".

\section{Conclusiones}

Goza de un amplio consenso la tesis, aquí también suscrita, según la cual las sociedades aymara y atacameña del norte de Chile se han transformado profundamente durante el último siglo y que esas transformaciones se asocian a fuerzas económicas, tendencias sociopolíticas y corrientes culturales de modernización que operan a escala regional, nacional y global (González H., 1996, 1997; González M., 1991; Guerrero, 1984, 1994; Gundermann, op. cit.; van Kessel, 1992; van Kessel y Guerrero, 1987). Se trata de procesos de formación de una economía capitalista, del desarrollo industrial regional y sus avatares, de la constitución de mercados, de la instalación del Estado nacional chileno sobre la zona, de la integración del territorio regional, de la definición de comunidades nacionales y regionales, de la secularización parcial del pensamiento y de los mundos de vida, de una visión de futuro como progreso y desarrollo, del advenimiento de la cultura de masas, etc. En esta medida, la dinámica social indígena debe referirse a condiciones y fuerzas externas que, procesadas por lógicas societales internas, modelan el contenido y la trayectoria de los cambios.

Esas transformaciones representan un proceso de drástica ampliación de espacios sociales y culturales en relación con los cuales se desenvuelve la experiencia individual y colectiva andina. Leídas en términos de la dinámica social andina esas transformaciones, especialmente las que tienen lugar durante los últimos cincuenta años, pueden analizarse como el paso de sociedades estructura- das en microrregiones a sociedades andinas regionalizadas. Por lo tanto, las microrregiones de origen colonial terminan por disolverse como marcos de estructuración económica y sociocultural, para dar paso a sociedades cuyo sistema social y marcos colectivos de experiencia se amplían hasta alcanzar la macro región norte de Chile. A propósito del pastoralismo tratamos, entonces, del cambio desde las microrregiones a la regionalización de la sociedad aymara y atacameña en cuanto proceso de incorporación indígena a una modernidad latinoamericana.

Lo anterior se manifiesta como complejidad de la sociedad y de los universos de significado que intervienen en la vida social. Se expresa en un plano económico como multiplicación de espacios económicos estructurados según lógicas mercantiles y diversificación de sujetos económicos. En uno social como diferenciación institucional, multiplicación de nexos y relaciones individuales y colectivas, desarrollo de las solidaridades electivas, etc. En uno simbólico como proliferación de mundos de vida, desarrollo de campos de significado e incremento de la producción, circulación y recepción de mensajes. Como un aspecto de lo anterior, el cambio conlleva una radical redefinición de la relación urbano rural; durante las últimas décadas lo rural y lo urbano no pueden entenderse sino como componentes de un mismo sistema integrado en el cual los sujetos rurales característicos del pasado, indígenas campesinos, dan paso a segmentos sociales situados en diversas posiciones de clase que articulan una también diversificada base de espacios económicos y sociales. El concepto de comunidad translocal (Gundermann, op. cit.) es empleado para destacar la continuidad de las relaciones rural urbanas reformadas por la inclusión indígena a los procesos de modernización regional. Los sujetos unitarios de antaño dan origen así a sujetos socialmente más complejos.

La sociedad campesina estructurada en las microrregiones de antaño ha dejado de existir tanto en la zona aymara como en la atacameña. El pastoralismo andino remanente manifiesta diferencias tecnológicas y sociales notables. De manera general puede aseverarse que pierde centralidad; se transforma en una actividad cuya importancia general para la economía, la sociedad y la cultura indígena es decreciente y, para algunos sectores 
indígenas, francamente periférica o insustancial. No se trata de la desaparición del pastoralismo, sino de su transformación. A este respecto, la pauta de cambio aymara es notablemente distinta de la atacameña. En el primer caso, el cambio se manifiesta como pérdida de centralidad económica y social y como redefinición de las prácticas del pastoralismo: éstas se realizan ajustándose a una sociedad indígena regionalizada. En el segundo, la pauta de cambios dirige esta actividad hacia su disolución: estarían dejando de presentarse las condiciones económico-sociales y las justificaciones culturales para la continuidad del pastoralismo andino. El que todavía permanece en la zona atacameña también se ajusta a una sociedad indígena regionalizada, pero las presiones que penden sobre ella son considerablemente más poderosas que en el caso aymara. Buscamos explicar esa diferencia a través de una hipótesis que destaca la integración económica del agro aymara con la región y la discontinuidad que éste presenta en el caso atacameño. Este hiato fue explicado destacando la regionalización atacameña mediante su inserción en los mercados de fuerza de trabajo minero, por diferencia con los mercados de productos campesinos y el sector terciario de la economía regional que concentran la participación aymara.

\section{BIBLIOGRAFIA}

\begin{abstract}
FOLLA, J. C. 1989
\end{abstract}

GAETE, A. 1974

GONZALEZ, H. Características de la migración cam1996 po ciudad entre los aymaras del norte de Chile, Documento de Trabajo, Corporación Norte Grande, Arica, Chile.

1996 Las agrupaciones de residentes aymaras urbanos en el norte de Chile: adaptaciones a la ciudad y vínculos con las comunidades de origen. Documento de Trabajo, Corporación Norte Grande, Arica, Chile.

1997 Economía y uso del espacio en la sociedad aymara actual". En Actas del Segundo Congreso Chileno de Antropología, Santiago, Chile, pp. 567-579.

1997 "La inserción económica de los migrantes aymaras en la ciudad: el trabajo como empresa familiar y la reproducción cultural". En Actas del Segundo Congreso Chileno de Antropología, Santiago, Chile, pp. 315-324.
GONZALEZ, H., H. GUNDERMANN y R. ROJAS. Diagnóstico y estrategia de desarrollo campesino en la I Región de Tarapacá. Corporación Norte grande - Taller de Estudios Andinos (TEA), Arica, Chile.

GOnZaleZ, S. Hombres y mujeres de la Pampa. 1991 Tarapacá en el ciclo del salitre. Ediciones Camanchaca, Taller de Estudios Regionales, Iquique, Chile.

1997 La escuela chilena en los Andes de Tarapacá. En A. Bello, A. Willson, S. González y P. Marimán (Eds.), Pueblos indígenas, educación y desarrollo, CEDEM - UFRO, Santiago de Chile.

GUERRERO, B. Movimiento pentecostal y corrientes 1984 modernistas en el altiplano chileno. En Cuadernos de Investigación Social, CIREN, Iquique, Chile.

1994 A Dios rogando... Los pentecostales en la sociedad aymara del norte grande de Chile. Tesis Doctoral, Department of Cultural Anthropology / Sociology of Development, Universidad libre de Amsterdam, Holanda.

GUNDERMANN, H. Ganadería aymara, ecología y forrajes: 1984 Evaluación regional de una actividad productiva andina. En Chungara $\mathrm{N}^{\circ} 12$, Universidad de Tarapacá, Arica, Chile, pp. 99-123. 
1987 Comunidades ganaderas, mercado y diferenciación interna en el altiplano chileno. En Chungara $\mathrm{N}^{\circ} 16-17$, pp. 233-250, Universidad de Tarapacá, Arica, Chile.

1998 De la comunidad de tierras a la comunidad translocal. Persistencia y cambio en las instituciones comunitarias de los aymarás del norte de Chile. Tesis Doctoral (MS), Centro de Estudios Sociológicos, El Colegio de México, México.

GUNDERMANN, H. y H. GONZALEZ. Tierra, agua y socie1995 dad atacameña, un escenario cambiante. En Agua, ocupación del espacio y economía campesina en la región atacameña, Pourrut, Pierre y Lautaro Nuñez (eds.), ORSTOM - UCN, Antofagasta, Chile, pp. 78-106.

1997 Contribución a la historia de la propiedad aymara. Corporación Nacional de Desarrollo Indígena, Santiago de Chile, 165 pgs.

HIDALGO, J. Indian Society in Arica, Tarapaca 1986 and Atacama, 1750-1793, and its Response to the Rebellion of Tupac Amaru. Tesis Doctoral, Universidad de Londres, Inglaterra.
VAN KESSEL, J. Holocausto al progreso. Los aymaras 1992 de Tarapacá. Hisbol, La Paz, Bolivia (edición ampliada de la publicación realizada en Holanda en 1981).

VAN KESSEL, J. y B. GUERRERO. Sanidad y salvación en 1987 el altiplano chileno: del yatiri al pastor. En Cuadernos de Investigación Social $\mathrm{N}^{\mathrm{o}}$ 21, Iquique, Chile.

MORALES, H. Pastores trashumantes al fin del mun1997 do. Memoria de Título en Antropología, Universidad de Chile, Santiago.

OBEREM, U. El acceso a recursos naturales de dife1981 rentes ecologías en la sierra ecuatoriana (Siglo XVI). En Contribución a la etnohistoria ecuatoriana ( $S$. Moreno y U. Oberem, Eds.), colección Pendoneros $\mathrm{N}^{\circ}$ 20, Instituto Otavaleño de Antropología, Otavalo, Ecuador, pp. 45-71.

SALOMON, F. The dynamic of the complementary 1985 concept. En Andean Ecology and Civilization, Shozo Mazuda, Izumi Shimada y Craig Morris (Eds.), University of Tokio Press, Japón.

WOLF, E. Los campesinos. Nueva Colección La1971 bor, Barcelona, España. 